\title{
Knock-In of Human BACE1 Cleaves Murine APP and Reiterates Alzheimer-like Phenotypes
}

\author{
Kaja Plucińska, Barry Crouch, David Koss, Lianne Robinson, Michael Siebrecht, Gernot Riedel, and Bettina Platt \\ School of Medical Sciences, College of Life Sciences and Medicine, University of Aberdeen, Institute of Medical Sciences, Foresterhill, Aberdeen AB25 2ZD, \\ Scotland, United Kingdom
}

Key neuropathological hallmarks of Alzheimer's disease (AD) are elevated levels of amyloid $\beta$-peptide (A $\beta)$ species generated via amyloid precursor protein (APP) endoproteolysis and cleavage by the rate-limiting $\beta$-site enzyme 1 (BACE1). Because rodents do not develop amyloid pathologies, we here investigated whether AD-like endophenotypes can be created in mice by expression of human bace1. To avoid pitfalls of existing models, we introduced hbace1 via knock-in under the control of the CaMKII $\alpha$ promoter into the safe HPRT locus.

We report amyloidogenic processing of murine APP in the hBACE1 mice (termed PLB4), resulting in the formation of toxic APP metabolites that accumulate intra- and extraneuronally in hippocampus and cortex. Pronounced accumulation of $\mathrm{A} \beta \beta^{\star} 56$ and $\mathrm{A} \beta$ hexamers in the absence of plaque deposition was detected in brain tissue from symptomatic PLB4 mice. Heightened levels of inflammation (gliosis) also appeared in several AD-related brain regions (dentate gyrus, hippocampal area CA1, piriform and parietal cortices) at 6 and 12 months of age. Behaviorally, deficits in habituation to a novel environment and semantic-like memory (social transmission of food preference) were detected from 3 to 4 months of age. Impairments in spatial learning strategies in long-term reference (water maze) and working memory (Y-maze) tasks presented at 6 months, and were distinct from reductions in locomotor activity and anxiety.

Overall, our data indicate for the first time that targeted, subtle forebrain-specific expression through single gene knock-in of hBACE1 is sufficient to generate $\mathrm{AD}$-relevant cognitive impairments amid corresponding histopathologies, confirming human BACE as the key parameter in amyloid pathogenesis.

Key words: amyloid; circadian; cognition; inflammation; memory; strategy

\section{Introduction}

Alzheimer's disease (AD), the most common type of dementia, is characterized by progressive cognitive deficits. The generation of amyloid $\beta(\mathrm{A} \beta)$ species from the amyloid precursor protein (APP), together with abnormal processing of tau, is a recognized key event conferring toxicity and contributing to neurodegeneration. Amyloidogenic endoproteolysis of APP is initiated by $\beta$-site APP cleaving enzyme 1 (BACE1), a type I transmembrane aspartyl protease (Vassar et al., 1999; Cai et al., 2001). Cleavage of APP generates a C-terminal membrane-retained fragment (CTF- $\beta$ ) and soluble $\operatorname{APP} \beta$ ( $\operatorname{sAPP} \beta)$, subsequent proteolysis via $\gamma$-secretase results in the formation of $\mathrm{A} \beta$. Although evidence for the causative involvement of BACE1 in human AD remains controversial (Nicolaou et al., 2001; Gold et al., 2003), BACE1 levels and activity increase with age and particularly AD status (Fukumoto et al.,

Received Jan. 30, 2014; revised June 24, 2014; accepted July 1, 2014.

Author contributions: G.R. and B.P. designed research; K.P., B.C., D.K., L.R., and M.S. performed research; K.P., B.C., D.K., M.S., G.R., and B.P. analyzed data; K.P., G.R., and B.P. wrote the paper.

We thank Roemex and the College for Life Science and Medicine at the University of Aberdeen for their generous support.

The authors declare no competing financial interests.

Correspondence should be addressed to either Bettina Platt or Gernot Riedel, School of Medical Sciences, College of Life Sciences and Medicine, University of Aberdeen, Institute of Medical Sciences, Foresterhill, Aberdeen AB25 2ZD, UK, E-mail: b.platt@abdn.ac.uk or g.riedel@abdn.ac.uk.

DOI:10.1523/JNEUROSCI.0433-14.2014

Copyright $\odot 2014$ the authors $\quad 0270-6474 / 14 / 3410710-19 \$ 15.00 / 0$
2002; Yang et al., 2003; Hébert et al., 2008), thus supporting BACE1 as an attractive therapeutic target.

A wide range of experimental studies have provided insight into the role of BACE1 in AD pathologies. Since its discovery (Sinha et al., 1999; Vassar et al., 1999), the impact of BACE1 deletion or partial reduction has been extensively studied (Roberds et al., 2001): minor consequences, such as subtle changes in anxiety and sensorimotor abilities (Kobayashi et al., 2008), as well as enhanced long-term depression, were reported in wild-type mice (Wang et al., 2008), whereas BACE1 manipulations in APP overexpression models prevented amyloid pathology, neurodegeneration, astrogliosis, as well as cognitive deficits (Cai et al., 2001; Luo et al., 2001, Laird et al., 2005; Ohno et al., 2007). Rescued long-term potentiation and improved cognitive performance were also reported after partial reduction of BACE in 5xFAD animals (Kimura et al., 2010). Conversely, human bace1 (hbace1) coexpression in mice carrying human $a p p_{\text {swe }}$ (Bodendorf et al., 2002; Mohajeri et al., 2004) or app 695 (Chiocco et al., 2004) accelerated APP processing and the release of toxic $\mathrm{A} \beta_{40-42}, \operatorname{sAPP} \beta, \mathrm{C} 99$, and C89 terminal fragments. These findings confirmed BACE1 as the key enzyme in amyloidosis and subsequent pathologies, and suggest inhibition of this target as a promising therapeutic strategy.

However, additional BACE1 substrates complicate the scenario, with $\sim 67$ putative substrates identified (Grüninger-Leitch 
et al., 2002; Hemming et al., 2009; Kuhn et al., 2012), though most of cleavage products are still poorly understood. The majority of BACE1 substrates are involved in signaling (Dislich and Lichtenthaler, 2012), e.g., regulation of cAMP/PKA signaling (Chen et al., 2012), control of voltage-gated sodium channels (Kim et al., 2007), and serotonergic transmission (Harrison et al., 2003), but BACE1 is also implicated in myelin sheaths formation of peripheral neurones and axon bundling (Willem et al., 2006).

Given the wealth of animal models (over)expressing app, tau, and presenilin (PS1), it is somewhat surprising that no comprehensive assessment exists regarding the hbacel expression per se on AD-relevant behavioral and cellular readouts. Here, we describe a novel transgenic hBACE1 mouse based on targeted knock-in. Our data show for the first time that human BACE1 is crucial for the generation of AD-relevant cognitive and cellular endophenotypes in the absence of significant plaque formation.

\section{Materials and Methods}

Animal husbandry

All animals were housed and tested in accordance with European (European Directive on the protection of animals used for scientific purposes; 2010/63/EU) and UK Home Office regulations, experiments were approved by the University Ethics Board and performed in accordance with the Animal (Scientific Procedures) Act 1986. Mice were bred and housed in positively pressured isolators at a commercial vendor (Harlan), and delivered to our facility several weeks before testing. Animals were subsequently group housed (up to 6 per cage; unless fighting between males required isolation) in same sex cohorts in open wire-top cages with ad libitum access to water and food at a circadian regime of $12 \mathrm{~h}$ (lights on at 7:00 A.M.) in a fully controlled environment $\left(20-21^{\circ} \mathrm{C}, 60-65 \%\right.$ relative humidity). Behavioral testing took place during the light period (weekdays only). The holding regime was adjusted when animals were under investigations (for details, see Behavioral analysis, below).

\section{Generation of hBACE1 knock-in mice and genotyping}

PLB4 mice were generated by targeted knock-in of single copy of human bace1 cDNA construct (hbace1, MIM 604252; GenBank accession no. AF190725; Fig. $1 A, B$ ) on unaltered endogenous bace $1^{+/+}$background under the control of mouse CaMKII $\alpha$ promoter cloned into the HPRT targeting vector (conducted by GenOway). The CaMKII $\alpha$ promoter ensures a neuron- and forebrain-specific expression of the transgene. Gene targeting and homologous recombination was performed in 1290la (E14) embryonic stem cells (in which a $35 \mathrm{~kb}$ of the hprt gene encompassing the $5^{\prime}$ UTR up to intron 2 was deleted) and these were subsequently injected into C57BL/6J blastocytes. Due to hprt being located on the X chromosome, heterozygous PLB4 females were mated with transgenic hemizygous males to generate heterozygous and homozygous females and hemizygous males. DNA samples were prepared from tail biopsies taken from female pups for Southern blot analysis (Fig. 1B). For confirmation of the presence of the recombined allele, the blotted genomic AvrII digestion was tested with the internal $5^{\prime}$ probe $\mathrm{D}$. Results validated the correct heterozygous status of 5 tested F1 females by detecting the 6.0 $\mathrm{kb}$ sized AvrII fragment of the recombined hprt allele. PLB4 offspring were crossed with C57BL/6 mice for six generations before a homozygous PLB4 line was established. Wild-type $\left(\mathrm{PLB}_{\mathrm{WT}}\right)$ control animals were derived from the $\mathrm{PLB}_{\mathrm{WT}}$ line, generated via the same knock-in and breeding regime (Platt et al., 2011).

Body weights were routinely recorded before behavioral testing, data shown are from animals at 3 months $\left(\mathrm{PLB}_{\mathrm{WT}}\right.$ : male $n=12$, female $n=$ 12; PLB4: male $n=12$, female $n=20), 6$ months $\left(\operatorname{PLB}_{\mathrm{WT}}\right.$ : male $n=20$, female $n=18$; PLB4: male $n=20$, female $n=20), 9$ months $\left(\mathrm{PLB}_{\mathrm{WT}}\right.$ : male $n=18$, female $n=10$; PLB4: male $n=20$, female $n=18$ ), and 12 months of age $\left(\mathrm{PLB}_{\mathrm{WT}}\right.$ : male $n=9$, female $n=12$; PLB4: male $n=10$, female $n=8$ ). Details of age, gender, and genotype of animals used for behavioral and molecular assessments are stated below for each individual procedure.

\section{Western blot}

Mice ( 6 months: $\mathrm{PLB}_{\mathrm{WT}}: n=6, \mathrm{PLB} 4: n=7 ; 12-14$ months: $\mathrm{PLB}_{\mathrm{WT}}: n=$ 5, PLB4: $n=6$; both genders) were killed and whole brains rapidly removed and quick frozen in liquid nitrogen. An additional transgenic group generated via targeted knock-in, $P L B 1_{\text {Triple }}$ mice, expressing mutant happ/htau/hps1 (Platt et al., 2011) was used for comparison with PLB4 mice (female PLB1 $1_{\text {Triple }}: N=4,6$-months-old). Tissues (hemibrains minus cerebellum and brainstem) were homogenized in RIPA buffer, samples stored and immunoblotted, adapted from our previous reports (Koss et al., 2013a). Here, 30 and $100 \mu \mathrm{g}$ of protein was run per lane in NuPage $4-12 \%$ sodium Bis-Tris electrophoresis gels (15 and 18-well Novex Gels, Life Technologies) and electroblotted on Nitrocellulose $(0.2 \mu \mathrm{m}$ pore size; Invitrogen $)$ membranes via the iBlot dry transfer system (Life Technologies). TBST was used for wash steps and dilution throughout the protocol (Tris buffer saline, 0.05\% Tween). Following blocking ( $5 \%$ milk powder in TBST), membranes were immunoblotted with anti-murine N-terminal APP (1:1000, Abcam), anti-human APP 6E10 (1:500, Covance), anti-oligomeric A $\beta$ MOAB-2 (1:500, Millipore; Youmans et al., 2012), and anti-human BACE1 (1:500; Calbiochem) antibodies, applied with 5\% BSA, $0.05 \%$ sodium azide, and TBST for $24 \mathrm{~h}$, followed by incubation with appropriate horseradish peroxidase-conjugated secondary antibodies (Calbiochem; anti-mouse or anti-rabbit at 1:5000 dilution). Three types of protein ladders were used to guide molecular weight reading: a broad range prestained protein marker (for 7-175 kDa bands; BioLabs), MagicMark XP Western protein standard (for 20-220 kDa bands; Life Technologies), or Novex Sharp prestained ladder (4-260 kDa; Invitrogen). Potential changes in tau expression were assessed in tissue from 6-month-old mice (HT-7; Abcam; 1:5000, PHF-1, CP13, and MC-1 antibodies 1:100, a generous gift from Peter Davies, Albert Einstein College of Medicine, NY). Additional hexafluoroisopropanol (HFIP; Apollo Scientific) disaggregation experiments were performed for validation of $\sim 56 \mathrm{kDa}$ bands as genuine oligomeric amyloid species. Here, 0,10 , and $20 \%$ HFIP was added to LDSand DTT-treated PLB4 and PLB ${ }_{\mathrm{WT}}$ brain homogenates (age: 6 months; $N=2$ per genotype) and run with concentration of $7.5 \mu \mathrm{g}$ per lane in $10-20 \%$ Tricine gels (Novex, Life Technologies), transferred to $0.2 \mu \mathrm{m}$ pore nitrocellulose membrane (iBlot transfer) and immunoblotted with anti-human 6E10 antibody (1:1000; Covance). Immunoblotting signals were visualized with enhanced chemiluminescent substrate $(0.015 \%$ hydrogen peroxide, $30 \mu \mathrm{M}$ coumaric acid containing Tris-HCl-dissolved $1.25 \mathrm{~mm}$ luminal, $\mathrm{pH}$ 8.5). Images were captured with a Vilber-Fusion chemiluminescence-imaging camera (Fusion Spectra Software FX). Due to saturated signal for full-length APP using the mAPP antibody (Abcam), immunoblots were truncated based on the prestained protein ladder and images were captured separately using exposure settings optimal for: (1) full-length APP,(2) A $\beta^{\star} 56$, and (3) CTF fragments. Coomassie Blue stain $\left(0.1 \%\right.$ Coomassie in $20 \%$ acetic acid and $\left.\mathrm{H}_{2} \mathrm{O}\right)$ was used a protein loading control (Welinder and Ekblad, 2011), because potential transgene-induced differences in traditional housekeeping proteins, such as GAPDH or $\beta$-actin, were reported previously in human AD (Gebhardt et al., 2010) and in AD mouse models (Eaton et al., 2013). For validation of Coomassie staining as an alternative to housekeeping protein loading control serial dilutions of $\mathrm{PLB}_{\mathrm{WT}}$ samples were immunoblotted with GAPDH (Santa Cruz Biotechnology) and sequentially stained with Coomassie (Fig. 1D). The extrapolated linear correlation between the two methods yielded $R^{2}=0.89(p<0.001)$, validating Coomassie Blue as a reliable loading control. Analysis of Western blots was performed using ImageJ software; all data were normalized to the Coomassie Blue and expressed relative to age-matched wild-type levels. Therefore, statistical reliability was probed between age and genotypematched groups using two-tailed $t$ tests.

\section{Immunoprecipitation}

Additional nonquantitative immunoprecipitation (IP) experiments were performed to directly compare the soluble RIPA-extracted 6E10immunoreactive $\mathrm{A} \beta$ species in PLB4 and $\mathrm{PLB}_{\text {Triple }}$ brain lysates in the absence of depolymerizing agents. Brain tissue from a pronuclear injection-derived APP/PS1 mouse (Borchelt et al., 1997) was used as a positive control (soluble brain fraction). Protein G Dynabeads (Invitro- 
A

Wild-type Hprt locus (C57BL/6 ES cells)

Deleted Hprt locus (E14 ES cells)

Targeting vector Hprt-HR

Recombined Hprt locus
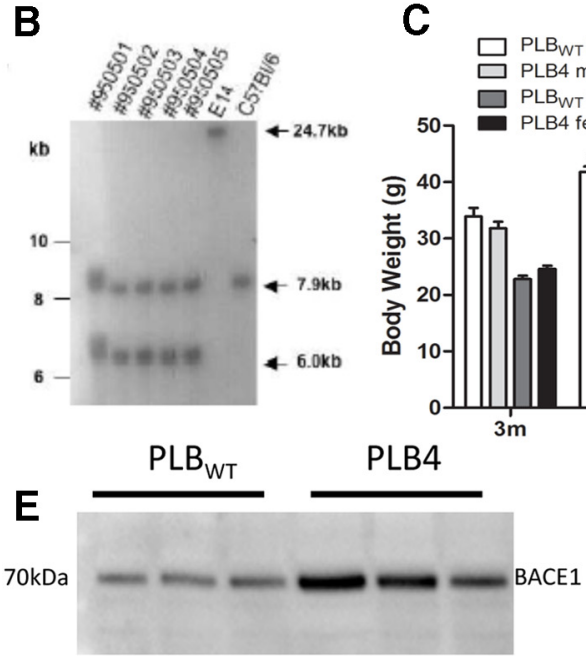

C

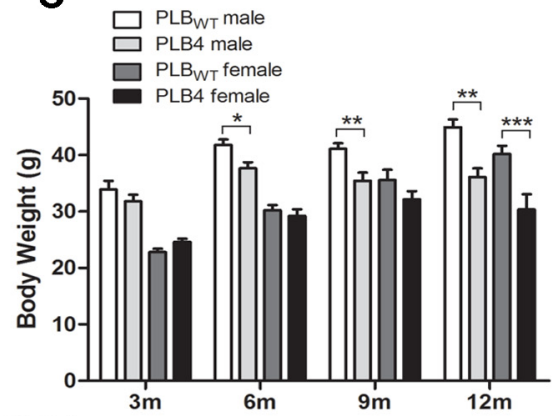

D $1510152025 \mu \mathrm{g} /$ lane
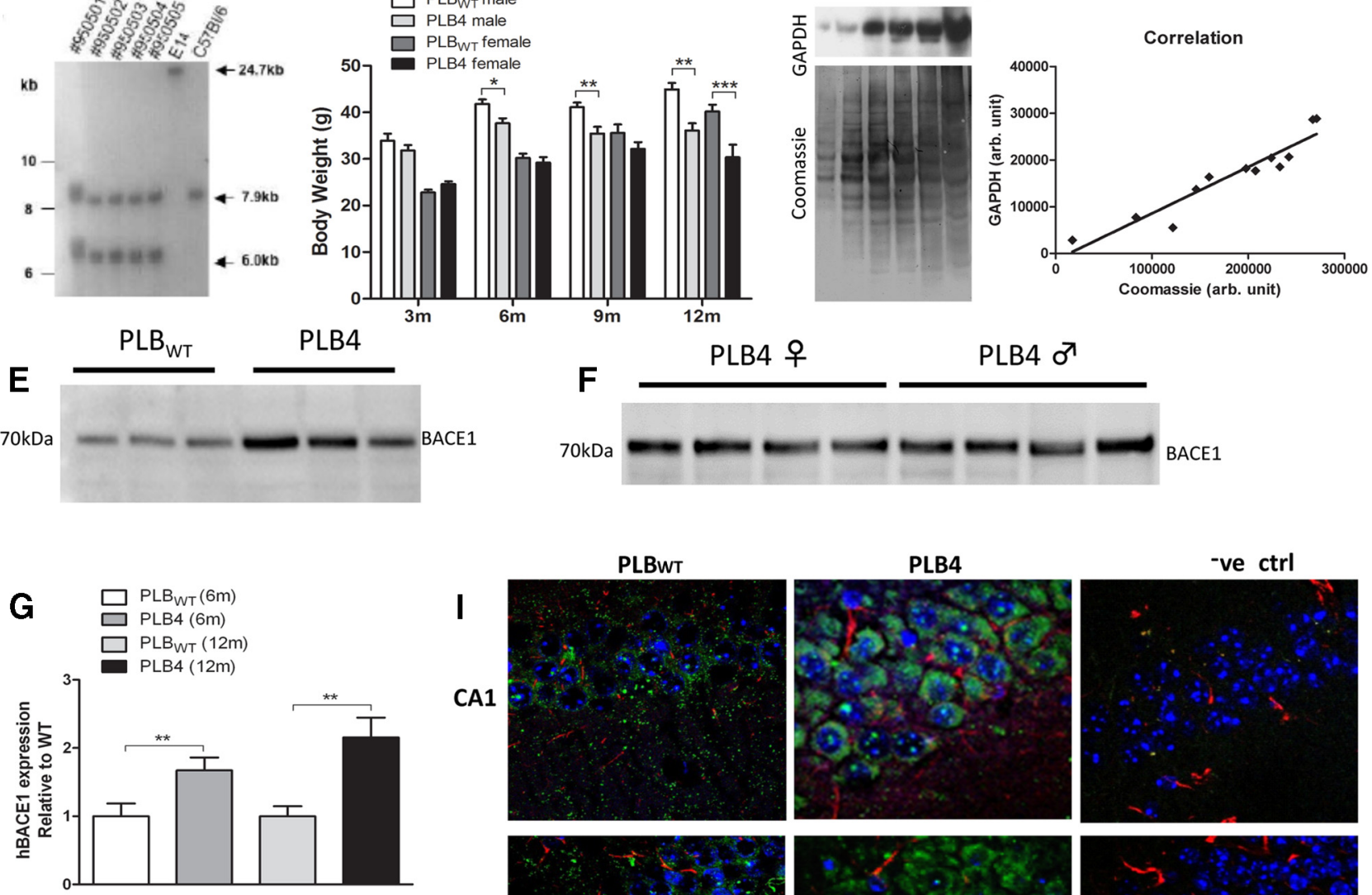

H
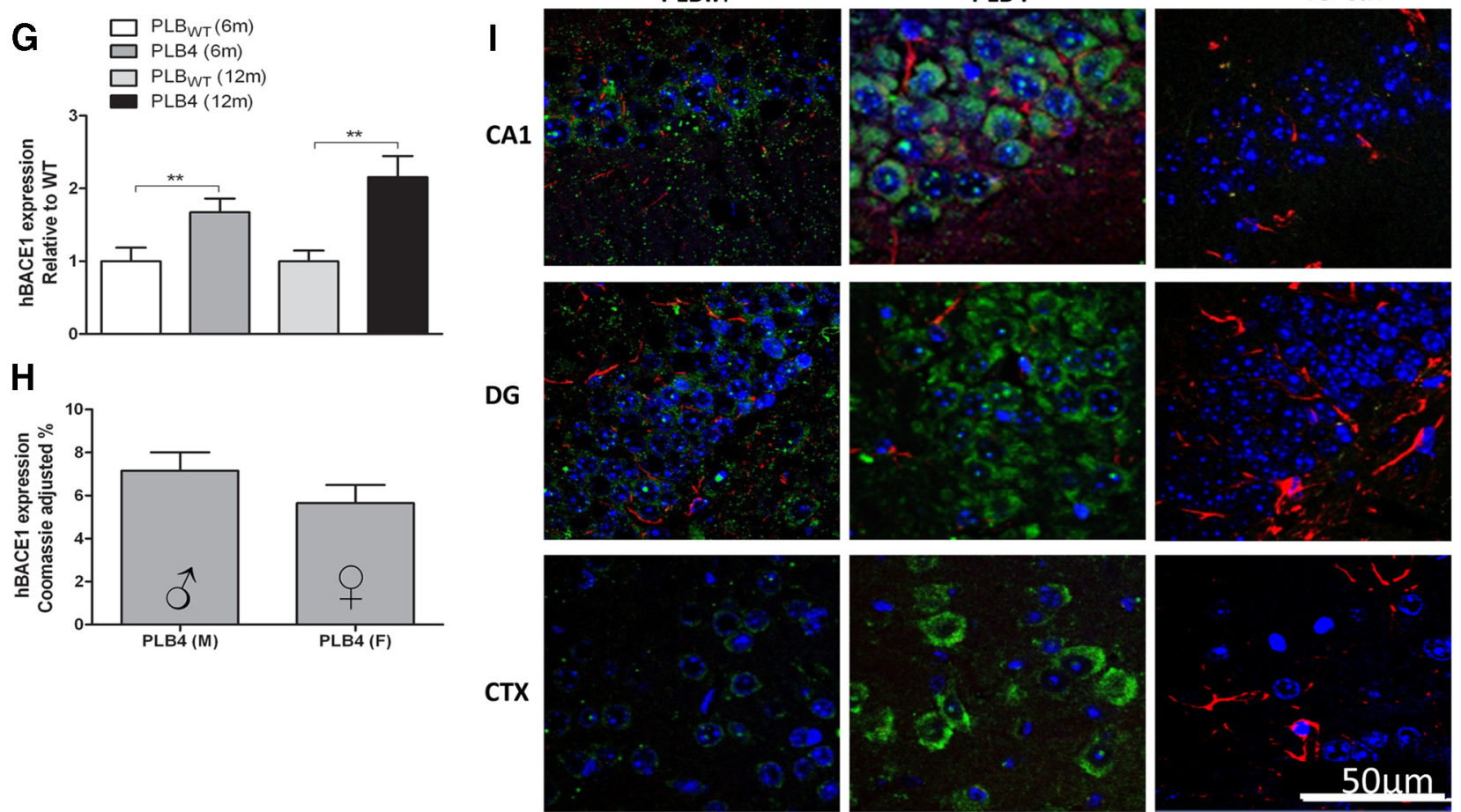

Figure 1. Construction of hbace1 transgene, genotyping and expression analysis of PLB4 mice. A, Schematic representation of the "Quick knock-in" strategy. Gray boxes represent exons. Solid line represents intronic sequence. Purple and blue rectangles represent CaMKIl $\alpha$ and hbace cDNA, respectively. The red rectangle represents the hprt promoter. $\boldsymbol{B}$, Southern blot results from the F1 generation. The genomic DNA samples of the tested F1 mice were compared with WT DNA (C57, E14). The $5^{\prime}$ digested DNAs were blotted on nylon membrane and hybridized with the $5^{\prime}$ probe D to validate zygocity of the hprt knock-in mutation in these animals ( $7.9 \mathrm{~kb}$ band: WT hprt allele, $6 \mathrm{~kb}$ : recombined hprt allele). C, Body weights of transgenic animals (Figure legend continues.) 
gen) were conjugated to $6 \mathrm{E} 10 \mathrm{IgG}(1.5 \mu \mathrm{g}$ beads; $10 \mu \mathrm{g} 6 \mathrm{E} 10)$, crosslinked by $5 \mathrm{~mm}$ Bis(sulfosuccinimidtyl)suberate $\left(\mathrm{BS}^{3}\right)$ and quenched in 1 $\mathrm{mm}$ Tris $\mathrm{HCl}$, before the addition of $200 \mu \mathrm{l}$ forebrain homogenates (prepared as above). Following a $10 \mathrm{~min}$ incubation period, immunodepleted samples were removed and the target antigen eluted in $50 \mathrm{~mm}$ glycine, $\mathrm{pH}$ 2.8. $6 \mathrm{E} 10$ antigen enriched samples were then prepared in loading buffer (as above) and $10 \mu \mathrm{l}$ of the resulting preparation were run alongside similarly treated immunodepleted samples. Tricine gels (10-20\%, Life Technologies) were used for electrophoresis and immunoblotting was performed as described above $(0.2 \mu \mathrm{m}$ pore nitrocellulose membrane, iBlot transfer).

\section{Immunocytochemistry}

Animals ( 6 months of age: $\mathrm{PLB}_{\mathrm{WT}}: n=4$, PLB4: $n=4 ; 12$ months of age: $\mathrm{PLB}_{\mathrm{WT}}: n=4$, PLB4: $n=6$; all mixed gender) were perfused transcardially with $0.9 \% \mathrm{NaCl}$ (saline), $\mathrm{pH} 5.5$, followed by $4 \%$ paraformaldehyde (Sigma-Aldrich) in PBS. The brains were fixed, wax embedded, sectioned, prepared, and stained as described previously (Koss et al., 2013b). For regional inflammatory expression brains were sectioned from bregma $-3.0 \mathrm{~mm}$ to $+2.5 \mathrm{~mm}$ to obtain several areas of interest: caudal and rostral hippocampi, amygdala $(\mathrm{Am})$, parietal $(\mathrm{Pt})$, and piriform (Pir) cortices. Primary antibodies used were rabbit anti-hBACE1 C-terminal (Calbiochem; 1:200 dilution), anti-APP/ $\beta$-amyloid antibody (6E10, Covance; 1:200 dilution), and monoclonal preconjugated GFAP-Cy3 (Glial Fibrillary Acid Protein, Sigma-Aldrich; 1:400 dilution). Primary antibodies were visualized with Bonds refined DAB staining kit (Leica Microsystems) or appropriate AlexaFluor 488 secondary antibodies (Invitrogen; goat anti-rabbit, 1:250). Nuclei were counterstained with either hematoxylin or DAPI (Prolong Gold with DAPI, 4',6-diamidino2-phenylindole dihydrochloride; Sigma-Aldrich). Immunohistochemical images were captured with a digital camera (Axiocam, Carl Zeiss) mounted on a Zeiss microscope (Axioskop 2 Plus) with waterimmersion lens $(\times 10, \times 40$, or $\times 100)$ or confocal microscope with oilimmersion lens ( $\times 63$, LSM700; Zeiss).

Quantification of regional (CA1, dentate gyrus, DG; parietal association cortex) immunoreactivity to $6 \mathrm{E} 10$ was performed using Fiji software (APP-positive cell counting), data were normalized to the total number of cells present in a region of interest (ROI) and expressed relative to wild-type (WT). Analysis and quantification of activated astrocytes, or extracellular APP labeling was performed using ImageJ software, and expressed as area stained (in percentage). Stereologically matched brains sections were analyzed (3-5 per animal), and all data expressed relative to WT. The sizes of ROIs were as follows: $600 \times 800 \mu \mathrm{m}$ for hippocampal and $800 \times 800 \mu \mathrm{m}$ for cortical areas. Additional histological analyses

$\leftarrow$

(Figure legend continued) were recorded at 3, 6,9, and 12 months ( $m$ ). Although body weights of transgenic mice were unaltered at 3 months, male PLB4 mice showed marked reduction in body mass at 6,9 , and 12 months of age, compared with age-matched control group. Female PLB4 showed similar trends and present with significantly decreased weights at 12 months of age. $\boldsymbol{D}$, Validation of Coomassie staining as an improved alternative to housekeeping proteinloading controls. Western blot image from 12-month-old PLB ${ }_{\mathrm{WT}}$ brain homogenates run at varying protein concentrations (1-25 $\mu \mathrm{g} / \mathrm{lane})$. Resulting nitrocellulose membranes were stained with the traditional housekeeping protein GAPDH $(1: 10,000)$, followed by Coomassie protein stain. Linear regression analysis from WT homogenates yielded a strong correlation $\left(R^{2}\right.$ $=0.89$ ) between densitometry measures of GAPDH and the total protein detected by Coomassie. $\boldsymbol{E}$, Representative Western blots verify hBACE1 protein $(\sim 70-75 \mathrm{kDa})$ expression in brain tissue of PLB4 animals stained with anti-human BACE1 specific antibody. $F$, Western blot examples comparing male and female expression levels. G, Quantitative hBACE1 analyses in PLB4 compared with nontransgenic animals at 6 and 12 months of age ( $n=6$ each) confirmed significantly increased levels of $\mathrm{hBACE} 1$ in PLB4 brains, no difference in expression was detected between males and females $(\boldsymbol{H}) . \boldsymbol{I}$, Confocal images of hBACE1 immunoreactivity in $P B_{W T}$ and PLB4 brain tissue at 6 months of age. hBACE1 (visualized with AlexaFluor 488; green) staining in DG, CA1 and cortex (CTX) was particularly intense at neural somata (nuclei indicated by DAPI; blue) and absent from astrocytes (GFAP; red). Negative control (-ve ctrl) images represent PLB4 tissue sections from secondary antibody control staining. Scale bar, $50 \mu \mathrm{m}$. Magnification $\times 63$. All data represent mean + SEM. Asterisks indicate difference to the control group; ${ }^{*} p<$ $0.05,{ }^{* *} p<0.01,{ }^{* * *} p<0.001$. were performed to determine levels of astroglyosis for specific learning phenotypes of 12-month-old PLB4 mice assessed in the open field water maze. "Good" and "bad" learners $(N=3$ per group) were chosen based on the highest deviation from the mean cognitive score (sum of path length during training days $1-4$; mean score $=26.2 \mathrm{~m}$; good learners: mean $<18 \mathrm{~m}$, bad learners: mean $>30 \mathrm{~m}$ ). Statistical reliability was probed using two-way ANOVAs (learning phenotype $\times$ brain region) or $t$ tests for data from age- and genotype-matched cohorts.

\section{Behavioral analysis}

Motor performance and motor learning (RotaRod). Two automated fourlane accelerating RotaRods (Model 33700-R/A; TSE; Robinson et al., 2012) were used to examine motor coordination and motor learning in 6-month-old animals ( $\mathrm{PLB}_{\mathrm{WT}}$ : male $n=9$, female $n=10$; PLB4: male $n=10$, female $n=10$ ). Testing consisted of four trials per day for 2 consecutive days with intertrial intervals of $2-3 \mathrm{~min}$. Each mouse was placed on the rotating rod, which accelerated from 1 to $45 \mathrm{rpm}$ over the trial time of $5 \mathrm{~min}$. Trials were terminated when animals fell off (or the maximum time was reached) and latency to descent (in sec) served as an indicator of motor coordination (linearly correlated with rotations sustained). Animals were allocated to lanes on different days following a Latin square design to counterbalance rod position and time of testing.

Gait analysis (CatWalk). Gait analysis was performed on the same cohort of 6-month-old mice (see RotaRod; $\mathrm{PLB}_{\mathrm{WT}}$ : male $n=9$, female $n=10$; PLB4: male $n=8,1$ excluded, female $n=10$ ) using the CatWalk apparatus (Noldus IT; CatWalk XT 8.1; Robinson et al., 2012). The apparatus consisted of an illuminated glass walkway and under-floor camera to record individual footprints. Mice were given three trials and a maximum time of $5 \mathrm{~s}$ each to traverse the glass plate and only one trial was used for analysis. Recorded data included the relative position, timing, pressure, and dimensions of each footfall. Parameters analyzed comprised step regularity, base of support (width between left and right paw), stride length in front and hindpaws, and a regularity index (percentage of occurrences of the 4 most frequently used footfall patterns).

Circadian activity and habituation to a novel environment (PhenoTyper). Locomotor and circadian activity patterns were assessed in mixed gender cohorts at 3 months ( $\mathrm{PLB}_{\mathrm{WT}}: n=11$, PLB4: $\left.n=13\right), 6$ months $\left(\mathrm{PLB}_{\mathrm{WT}}: n=10\right.$, PLB4: $\left.n=14\right)$, and 12 months of age (PLB $\mathrm{PLT}_{\mathrm{WT}}: n=12$, PLB4: $n=19$ ), using a PhenoTyper homecage system (Noldus IT) as described previously (Platt et al., 2011; Robinson et al., 2013). Ambulatory activity was continuously registered through infrared-sensitive cameras and tracked at 12.5 samples/s for 7 consecutive days using the multiarena module of Ethovision 3.1Pro software (Noldus IT). Parameters analyzed included distance moved as the main dependent variable for activity; we also explored the time spent in the food zone as a proxy for overall food intake (Riedel et al., 2009; Robinson et al., 2013).

Habituation to the new environment (first $3 \mathrm{~h}$ of recordings on day 1 ) served as an indicator of exploratory behavior and the animals' capability to create a spatial representation of their environment (Vianna et al., 2000). Data were extracted in $10 \mathrm{~min}$ bins and analyzed using a one phase decay fit to graphically track habituation curves of both PLB ${ }_{\mathrm{WT}}$ and PLB4 animals. Initial novelty-induced exploration (Y0), time constant (tau), and plateau (stable $y$-axis level; i.e., activity; Robinson et al., 2013) were calculated; note that the decline in activity occurs at the rate constant $K$ (inverse of tau) and is a proxy for the speed of the habituation.

Data for days 3-7, i.e., when animals were fully habituated to the cages, were transformed by our in-house software (Mnimi) and results averaged into (1) hourly bins over $4 \mathrm{~d}(94 \mathrm{~h})$ and (2) means for $12 \mathrm{~h}$ light/dark phase. Ambulation was analyzed using a two-way ANOVA (genotype and time as factors) with repeated measures; habituation was analyzed by nonparametric statistics. Alpha was set to $5 \%$.

\section{Anxiety}

Light/dark box. Anxiety behavior in the light/dark box (LDB) was assessed at 6 months of age ( PLB $_{\mathrm{WT}}: n=11$, PLB4: $n=12$; mixed gender). The LDB apparatus was constructed according to Crawley and Goodwin (1980) and consisted of two Perspex boxes: a big open white compartment $(30 \times 30 \times 30 \mathrm{~cm})$ brightly illuminated by a $60 \mathrm{~W}$ desk lamp $(550$ lux); and a smaller dark compartment $(30 \times 20 \times 25 \mathrm{~cm})$ covered with 
Plexiglas lid (5 lux). The compartments were connected by an aperture at floor level. Animals were individually placed in the brightly lit compartment facing the opening and allowed to freely explore the apparatus for $10 \mathrm{~min}$. Time spent in the dark compartment and motor activity (distance moved, video-tracked using Ethovision in the light compartment) were taken as indicators of anxiety and exploration, respectively. Distance moved was normalized compared with time spent in the light compartment to compensate for unequal durations in zones, i.e., activity data are expressed as mean centimeters per minute.

Elevated plus maze. Fear-related phenotypes were examined further in the elevated plus maze (EPM; Pellow et al., 1985) using a different cohort of animals at 6 months of age ( PLB $_{\mathrm{WT}}: n=11$; PLB4: $n=11$; mixed gender). The EPM consisted of a gray cross-shaped Perspex apparatus (arms: $35 \mathrm{~cm}$ long $\times 5 \mathrm{~cm}$ wide; central square: $5 \times 5 \mathrm{~cm}$ ). Two opposite arms were delimited by vertical walls (closed arms), and the other two had unprotected edges (open arms). The apparatus was elevated $42 \mathrm{~cm}$ above the laboratory bench, in a dimly illuminated room (light intensity in open arms: 95 lux; in closed arms: 28 lux). At the start of the 5 min trial, each mouse was placed in the central square of the maze facing an open arm. Visits to open and closed arms and the frequency of open arm entries were recorded by an overhead camera (Ethovision software). Time spent in open arms and distance moved served as measures of anxiety and exploratory behavior.

\section{Spatial working memory: the Y maze}

Spontaneous spatial alternation was assessed at 3 months $\left(\mathrm{PLB}_{\mathrm{WT}}: n=\right.$ 13; PLB4: $n=14), 6$ months ( PLB $_{\mathrm{WT}}: n=11$; PLB4: $\left.n=13\right)$, and 12 months of age ( $\mathrm{PLB}_{\mathrm{WT}}: n=15$; PLB4: $\left.n=20\right)$ with mixed gender cohorts. Animals were placed individually into the Y maze $(60 \times 10 \times 10$ $\mathrm{cm}$ ) and allowed to freely explore the apparatus for $10 \mathrm{~min}$. The activity of the subjects was recorded by an overhead camera and tracked by Ethovision. The number of correct alternations as well as the alternation index (in percentage) based on triplet combinations (i.e., ABC) served as main indices of spatial working memory. The total number of transitions and distance moved were taken as proxies for overall activity.

\section{Spatial reference memory: the open-field water maze}

Spatial memory in the open-field water maze (OFWM) was assessed using a $150-\mathrm{cm}$-diameter and 50-cm-high white Perspex pool, filled with water $\left(21 \pm 1^{\circ} \mathrm{C}\right)$ and surrounded by several fixed room cues visible from the pool (Platt et al., 2011; Ryan et al., 2013). Animals (mixed gender: 6 months, $\mathrm{PLB}_{\mathrm{WT}}: n=14$; PLB4: $n=14 ; 12$ months, $\mathrm{PLB}_{\mathrm{WT}}: n=14$; PLB4: $n=19$ ) were allocated to target platform locations (rising platforms; Ugo Basile) and released from four different sites (S, W, N, E), with a maximum swim time of $90 \mathrm{~s}$. Following visible platform training [for $1 \mathrm{~d}, 4$ trials, $30 \mathrm{~min}$ intertrial interval (ITI), curtains drawn], four training days commenced with a submerged platform (no curtains drawn). Mice received four trials each day (ITI: $30 \mathrm{~min}$ ) and swim paths to platform (acquisition time on platform: $30 \mathrm{~s}$ ) were recorded and tracked online (Any-Maze software, Ugo Basile). Standard parameters analyzed included: (1) path length to platform and (2) swim speed to determine spatial cognition and activity parameters, respectively. After the last trial (delay: $1 \mathrm{~h}$ ), the platforms were lowered and a probe trial (60 s) was performed. Here, the time spent in the target quadrant was determined.

\section{Classification of search strategies}

Acquisition learning of the platform location in the water maze typically involves the progressive improvement toward more spatially accurate swim paths. These have been identified previously (Wolfer and Lipp, 2000; Gil-Mohapel et al., 2013) and applied to the analysis of spatial learning in AD mice (Janus, 2004; Brody and Holtzman, 2006). We here developed a MATLAB (MathWorks) script of strategy selections and hierarchical priorities based on the description by Garthe et al. (2009). Its translational value was recently confirmed in a human study using a virtual water maze analog (Schoenfeld et al., 2010). In total, >1300 swim tracks were analyzed and classifications visually confirmed by two unbiased experimenters for one of the following eight strategies: (1) Wall hugging (persistent swimming along the periphery, 35\%, of the pool), (2) random search (swim path covering most of the pool in wide circles), (3) scanning (search path restricted to mainly the center of the pool), (4) chaining (circular swimming in clockwise or anticlockwise fashion at a distance from wall matching the distance of the platform location), (5) directed search (directional triangular swimming from release site to target), (6) focal search (direct swim to platform vicinity followed by focal searching in a small radius surrounding the target), (7) direct swim (straight swim and climbing onto platform), and (8) any other swim pattern not falling into the categories above. As the latter category was rare ( $<2 \%$ of total swims) in all genotypes and ages, they were not considered here. During acquisition of the spatial location of the submerged platform, animals progress through these categories and become more spatially oriented. To avoid misclassifications, a hierarchical search was implemented such that spatial strategies were interrogated first. After each trial was categorized into one of the above search patterns, we established daily means (in percentage) per group. Finally, we explored path efficiency based on pixel analysis of the path for each swim strategy, calculated as $E=$ (hypothetical perfect path/total recorded path $) \times 100$. As a result, values scatter between 100 (perfect trial) and 0 (platform not found).

\section{Semantic memory: social transmission of food preference}

A semiautomated version of the Social Transmission of Food Preference (STFP) test was developed in our laboratory, based on the principles laid out by Galef and Wigmore (1983). In this task, a food bias of an "observer" animal is induced via social interaction with a "demonstrator" mouse ( previously exposed to distinctly flavored food); olfactory memory is subsequently interrogated in a food preference test. STFP was assessed in animals kept in PhenoTyper home cages at 4 months $\left(\mathrm{PLB}_{\mathrm{WT}}\right.$ : $n=11$; PLB4: $n=21$; mixed gender) and 6-7 months of age (PLB $\mathrm{PT}_{\mathrm{WT}}$ : $n=22$; PLB4: $n=22$; mixed gender). Animals were habituated to the novel environment for $3 \mathrm{~d}$ with ad libitum access to food pellets and water. Following habituation mice were exposed to ground mouse chow in jars located in corners for a period of $24 \mathrm{~h}$ (habituation and determination of subject's spatial preference for food jar location). Before testing, animals were food deprived overnight $(16 \mathrm{~h})$. On the following morning, the demonstrator mice were exposed to novel food flavors ( $1 \%$ cinnamon-mixed chow or $2 \%$ cocoa-mixed chow) for $30 \mathrm{~min}$ and subsequently placed in a social interaction cylinder $(8 \mathrm{~cm}$ in diameter, $20 \mathrm{~cm}$ tall) positioned in the PhenoTyper cage allowing the observer mice social interaction (SI) with the demonstrator. This SI phase was recorded for 30 min (simultaneous recordings of 24 animals in individual cages) and interaction measured as time spent and distance moved by the observer in the interaction zone ( $4 \mathrm{~cm}$ around the cylinder). Subsequently, the demonstrator mice were removed and following a delay of (1) $15 \mathrm{~min}$ (short-term memory test; STM), and (2) 24 h (long-term memory test; LTM), observer mice were exposed to two jars containing novel flavors ( $1 \%$ cinnamon-mixed chow and $2 \%$ cocoa-mixed chow). Jars with correct (matching flavor of demonstrator) food flavor were placed in the least preferred corners to avoid a spatial bias. The activity of the subjects during the food preference test was recorded for $30 \mathrm{~min}$ for STM or $12 \mathrm{~h}$ for LTM, with no further food deprivation between recordings. Preference for correct food (as percentage of total food intake), as well as food intake (in grams, correct vs incorrect) were taken as main indices of intact semantic memory. Other parameters analyzed for the test phase were time spent $(\mathrm{sec})$ and frequency of visits to the food jars and jar vicinity zones, and overall distance moved $(\mathrm{cm})$.

\section{Statistics}

Statistical analyses were performed with Prism (V.5 GraphPad) using ANOVA (one- or two-way, as appropriate) followed by suitable posttests. Data from more than one trial or time point (Weight, RotaRod, PhenoTyper, OFWM) were probed using repeated-measures (RM) twoway ANOVA (time $\times$ age or genotype as factors). Comparisons to the levels of chance using Wilcoxon signed-rank test are also reported (chance values: Y-maze alternation index: 33.33\%; STFP: 50\%, water maze probe trial: $25 \%$ ). For detailed analysis of water maze strategies, $\chi^{2}$ analysis was conducted on the relative frequencies of occurrence between age groups of identical genotypes over $4 \mathrm{~d}$, and between genotypes at the same age for the final day of acquisition learning. Individual data pairs were tested with paired or unpaired $t$ tests as appropriate. For all procedures, $p<0.05$ was considered reliable. 


\section{Results}

Molecular and immunohistochemical confirmation of gene expression

Successful insertion of the transgene (Fig. 1A) was confirmed by the presence of the $6.0 \mathrm{~kb}$ sized AvrII fragment of recombined hprt allele in heterozygous PLB4 DNA extracted from tail samples using Southern blot analysis (Fig. 1B); this was absent in corresponding WTs.

Human BACE1 protein expression in PLB4 animals was determined via Western blot analysis of cell lysates prepared from brain extracts (Fig. $1 E-G$ ) and quantified based on the Coomassie Blue method, validated versus GAPDH in $\mathrm{PLB}_{\mathrm{WT}}$ samples (Fig. 1D). Some cross-reactivity with mouse BACE is suggested by the presence of faint bands in $\mathrm{PLB}_{\mathrm{WT}}$ samples, however, BACE levels were $\sim 1.8$ fold and $\sim 2.2$-fold higher in transgenic mice compared with nontransgenic controls at 6 and 12 months of age, respectively (all $p<$ 0.01; Fig. $1 G$ ). Bands detected at $70-75 \mathrm{kDa}$ are indicative of the mature (glycosylated) form of the protein (Cole and Vassar, 2007). Further analysis revealed no effects of gender on levels of hBACE1 protein expression ( $p=0.12 ; n=5$ per gender; Fig. $1 H)$.

Immunofluorescent labeling for hBACE1 in the hippocampus of 6- and 12-month-old mice (Fig. 1I; examples shown are from DG, CA1, and parietal cortex), double-labeled for astrocytes (GFAP), further confirmed hBACE1 expression in forebrain areas of PLB4 animals, in agreement with the CaMKII $\alpha$ promoter profile (Odeh et al., 2011). The lack of overlay comparing glial with BACE labeling verified the predominantly somatic hBACE1 immunoreactivity in neurones with staining largely absent from astrocytes. Strongest labeling was detected in the DG. PLB ${ }_{\mathrm{WT}}$ brain tissue exhibited again very low but apparent levels of immunoreactivity to the hBACE1 antibody, indicative of some species cross-reactivity due to the close homology of mouse and human BACE1 (Sambamurti et al., 2004).

\section{Breeding and general health}

Breeding, litter size, overall health, and attrition rates were not altered in PLB4 compared with $\mathrm{PLB}_{\mathrm{WT}}$ mice. Body weights of transgenic animals did not differ at 3 months of age compared with control animals $(F<1, p>0.05)$, but pronounced effects of genotype were detected from 6 to 12 months of age independently of gender (two-way ANOVA, males: $F_{(1,104)}=29.61, p<$ 0.001; females: $F_{(1,80)}=14.29, p<0.001$; Figure $\left.1 C\right)$. Interestingly, closer inspection revealed that whereas female PLB4 mice sustained normal body mass until 9 months of age (marked reductions in body weights at 12 months of age; Bonferroni posttest: $p<0.001$ ), male PLB4 animals were significantly lighter than their WT controls from 6 month of age onward (Bonferroni post-tests, 6 months: $p<0.05,9$ months: $p<0.01,12$ months: $p<0.01)$. Notably, in contrast to $\mathrm{PLB}_{\mathrm{WT}}$ there was no further weight gain in PLB4 mice from 6 to 12 months of age independent of gender (ranging from 35.5-37 g and 29.5-32 $\mathrm{g}$ on average in males and females, respectively), thus leading to significantly lower body weights in the older PLB4 cohorts.

\section{Behavioral changes and cognitive deficits in PLB4 mice Intact motor coordination and gait}

Motor performance tests using the RotaRod suggested that there was no difference in untrained motor coordination (measured as mean of the two initial trials, \pm SEM, PLB $_{\mathrm{WT}}$ : $40.5 \pm 2.8 \mathrm{~s}$; PLB4: $34.4 \pm 3.9 \mathrm{~s} ; t=1.3, \mathrm{df}=2, p=0.33$, two-tailed $t$ test). Similarly, motor learning recorded over eight trials did not differ between genotypes $\left(F_{(1,259)}=1.6 ; p=0.2 ;\right.$ Fig. $\left.2 A\right)$, but there was a reliable trial effect $\left(F_{(7,259)}=17.3 ; p<0.0001\right)$ confirming improvements in the ability to master the task. Although some minor differences appear (Fig. 2A), a gender comparison did not yield any reliable anomalies in the PLB4 cohorts (all $F<1.3$ ).

The same animals were also tested for their gait using the CatWalk paradigm. Although there was no genotype effect for base of support $\left(F_{(3,64)}=1.8, p=0.15\right)$, the width between front paws was considerably smaller in both genotypes and genders relative to hindpaws (Fig. $2 B ; F_{(3,64)}=90.5 ; p<0.0001$ ). Also, the regularity index as a proxy for the two most frequently expressed cruciate and alternate foot print patterns showed no phenotype or gender effect (Fig. $2 C ; F<3 ; p>0.05$ ), but the stride length was significantly reduced in PLB4 mice (Fig. 2D; genotype/gender: $\left.F_{(3,139)}=22 ; p<0.001\right)$ with no difference between front or hindpaws $\left(F_{(1,139)}=2.3 ; p=0.13\right)$. Overall, data reveal minor differences in gait in PLB4 mice not congruent with a severe motor phenotype in this transgenic model.

\section{Delayed habituation and global reduction in ambulatory activity in PLB4 mice}

Analysis of habituation (i.e., the first $3 \mathrm{~h}$ of recordings) as an index for nonassociative learning revealed an overall significant difference between genotypes at all age groups as well as an interaction with time bin $(F>6, p<0.0001$; Fig. $3 A-D)$. At all ages, PLB4 mice were more active than PLB $_{\mathrm{WT}}$ and presented with a reduced slope during habituation. Subsequent analyses of activity patterns within a given age group yielded a strong trend at 3 months $\left(F_{(1,374)}=4 ; p=0.052\right)$ and reliable differences at 6 months $\left(F_{(1,374)}=8.4 ; p<0.01\right)$ and 12 months $\left(F_{(1,510)}=5 ; p<\right.$ 0.05 ; Fig. $3 A-C)$. Higher levels of activity and delayed habituation in PLB4 groups was mathematically fitted to a nonlinear exponential decay function (Robinson et al., 2013) which corroborated the results of the activity data (all $F>14, p<0.0001$ ). Interestingly, there were no differences in initial ( $\mathrm{Y} 0)$ or plateau activity between genotypes and ages, but an extended half-life of the decay (tau time constant) emerged for PLB4 at all ages (Fig. 3D).

A strong aging effect was detected in PLB4 mice during habituation (effect of age: $F_{(2,731)}=5.9 ; p<0.01$; interaction effect: $F_{(34,731)}=3.5 ; p<0.001$; Figure $\left.3 D\right)$, whereas no similar trends were observed in $\mathrm{PLB}_{\mathrm{WT}}(F<3, p>0.05)$. Overall, this phenotype is strong support for the notion that there is no overall movement deficit in PLB4 mice, but reduced cognitive processing during habituation (Robinson et al., 2013).

Circadian activity in habituated animals (distance moved in hourly bins for a total of 4 consecutive days at all age groups; Fig. $3 E-G$ ) analyzed with a two-way RM ANOVA [genotype/age as between-subject and time (bin) as within-subject factor] attained an effect of genotype/age $\left(F_{(5,6789)}=5.5 ; p<0.001\right)$, an effect of time $\left(F_{(93,6789)}=35 ; p<0.0001\right)$, as well as an interaction $\left(F_{(465,6789)}=2.6 ; p<0.0001\right)$. Further analyses within the individual age groups substantiated that PLB4 animals at the age of 3 months did not differ from $\operatorname{PLB}_{\mathrm{WT}}(F<1$, Fig. $3 E)$ and both genotypes showed the C57BL/6-typical circadian pattern with nocturnal activity peaks. At 6 months of age (Fig. $3 F$ ), circadian rhythms were maintained, but motor activity of PLB4 animals was drastically reduced $\left(F_{(1,2046)}=26.6, p<0.0001\right)$; a similar comparison at 12 months showed a trend but did not attain reliability $\left(F_{(1,2697)}=3.3, p=0.08\right.$; Fig. $\left.3 F\right)$ possibly due to a progressive reduction in activity in $\mathrm{PLB}_{\mathrm{WT}}$. Data pooled for light/ dark phase further confirmed the decrease in locomotor activity of PLB4 mice at 6 months $\left(F_{(1,22)}=26, p<0.001\right)$ during both light $(p<0.05)$ and dark periods $(p<0.001$; Fig. $3 H)$. 
A

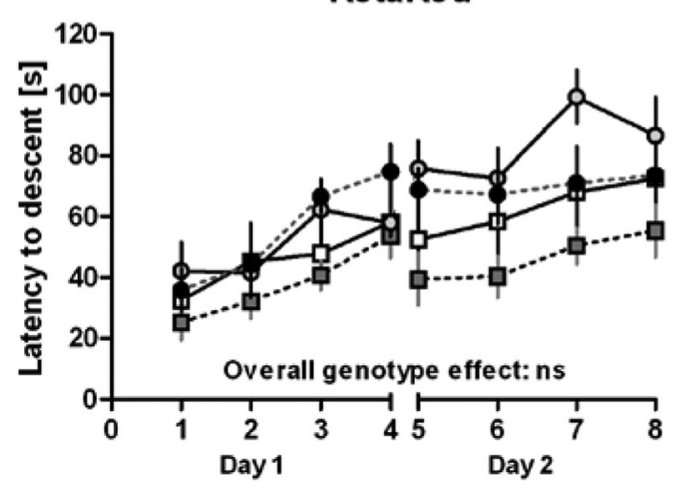

C

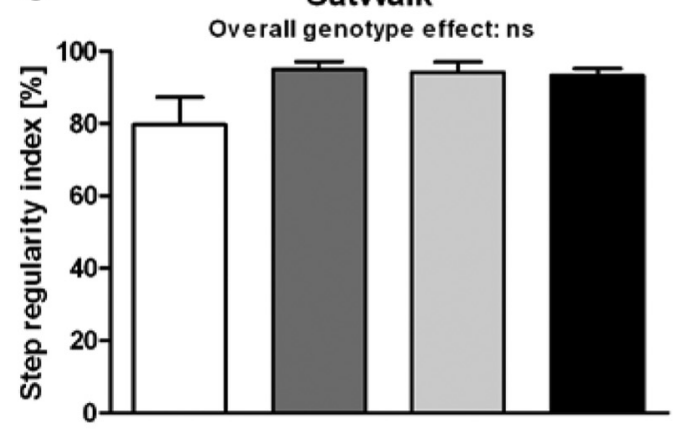

B
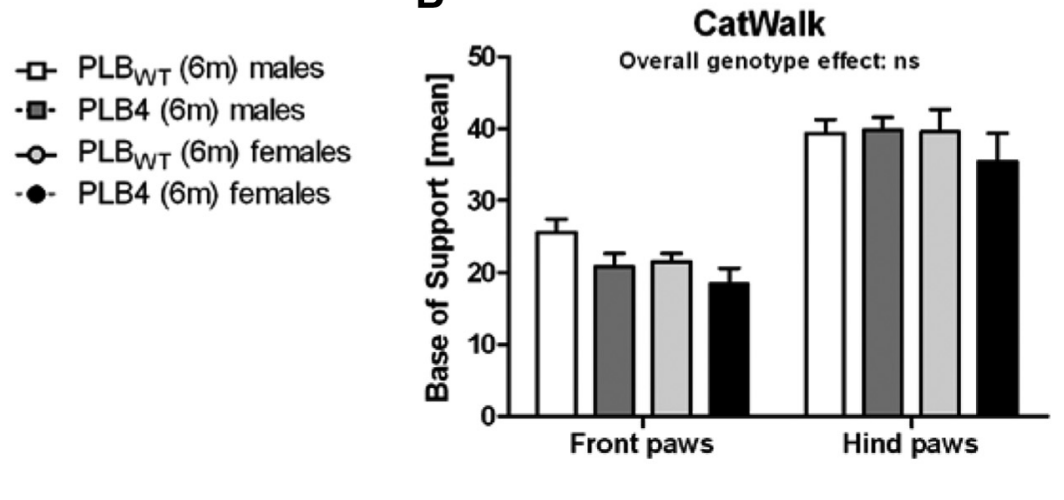

D

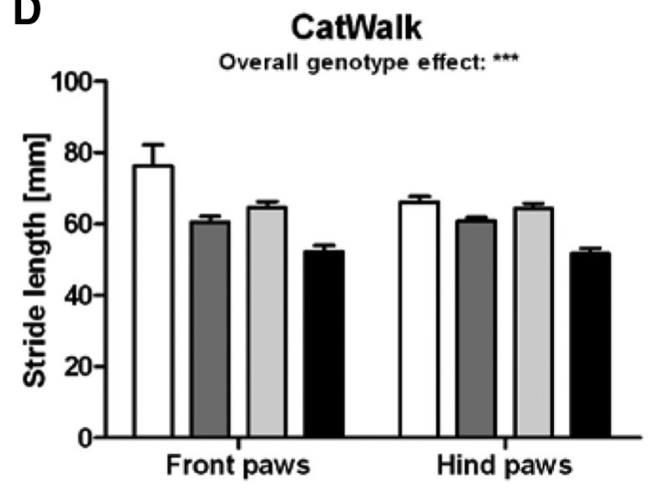

Figure 2. Motor coordination and gait assessments in 6-month-old PLB ${ }_{W T}$ and PLB4 mice. $A$, Latency of descent from RotaRod was unaffected in hBACE1 mice (no overall genotype effect) and both PLB $B_{W T}$ and PLB4 mice displayed intact motor learning. $B$, Analysis of gait in the CatWalk test confirmed intact motor function of PLB4 mice, with preserved base of support in both front and hindpaws, and $(\boldsymbol{C})$ step regularity. $\boldsymbol{D}$, Both male and female hBACE1 mice presented with decreased stride length compared with gender-matched PLB $B_{W T}$ controls. All data represent means \pm SEM. ns, Not significant; ${ }^{* * *} p<0.01$.

No age effect was obtained in $\mathrm{PLB}_{\mathrm{WT}}$ mice but an interaction emerged between age and phase $(3,6$ and 12 months groups, two-way ANOVA, effect of age: $F<1, p>0.05$; interaction: $\left.F_{(3,41)}=3.66, p<0.05\right)$, whereas a robust age-dependent change in activity was detected in the transgenic group (effect of age: $F_{(2,43)}=9.5, p<0.001$; interaction: $\left.F_{(2,43)}=13.9, p<0.001\right)$, which was particularly apparent during the dark phase at both 6 and 12 months compared with 3 months (Fig. $3 F, G$ ).

As a follow up to the reduced body mass observed in PLB4 mice (Fig. 1C), further analysis of time spent in the food zone as a measure for food intake (Riedel et al., 2009) was investigated. Here, the time spent in both food and water zones at 3, 6, and 12 months of age were not found to differ between PLB4 mice and age- and gendermatched controls ( $F<1, p>0.05$; data not shown).

\section{Alleviated anxiety and exploratory phenotypes in novel environments}

As evidence for activity changes was uncovered in PLB4 mice from 6 months of age, we further investigated fear-related behaviors as putative confounding factors in this age group. Both the LDB and EPM suggested an anxiolytic phenotype of PLB4 mice. In the LDB, PLB4 animals remained significantly longer in the light compartment (Fig. $4 A ; p=0.03$ ), and a corresponding strong trend (time in open arms) was also observed for the EPM paradigm (Fig. $4 B ; p=0.08$ ). Total distance moved revealed trends for increased exploration in the EPM (Fig. 4C; EPM: $p=$ 0.08 ), while activity in the LDB (corrected for the time spent in the lit compartment) was not altered $(p>0.05)$ in PLB4 mice. Representative activity traces obtained during the LDB and EPM testing are shown in Figure 4D.
Spatial working memory deficits in PLB4 mice emerge at 6 months of age

Because non-associative learning was deficient at 6 months of age, we also examined spatial working memory performance in a spontaneous alternation task in the Y-maze. Based on the global alternation index (Fig. 5A) we observed a significant interaction between genotype and age as factors $\left(F_{(2,80)}=4.2 ; p<0.05\right)$. This was due to deficient alternations in PLB4 animals at 6 months of age $(t=2.52, p<0.01)$, but there was no difference compared with $\mathrm{PLB}_{\mathrm{WT}}$ at 3 or 12 months. Closer inspection suggests that this effect was ultimately caused by an improved performance of controls at 6 months of age. It is likely that the overall higher activity in both genotypes at 3 months of age, indicated by total number of transitions, impacts on alternation behavior, as confirmed by the significant effect of age $\left(F_{(2,80)}=21.2, p<0.001\right.$; Fig. $5 B$ ). At 6 and 12 months of age, we noted trends for elevated locomotor activity (distance moved) of PLB4 mice compared with wild-type ( $p=0.08$ and $p=0.1$, respectively; data not shown), confirming an exploratory phenotype of our hBACE1 transgenic mice (Fig. $3 A$ ).

hBACE1 expression decreases spatial precision in the OFWM

Next, cognitive performance was evaluated in the OFWM. The length of the swim path in the visual platform trials did not differ between genotypes at any age ( $p>0.05$; data not shown). However, reliable age- and genotype-related deficits in spatial acquisition were obtained with increased path length to find the hidden platform in PLB4 mice. This was significant at both 6 and 12 months of age (two-way RM ANOVA; genotype effect at 6 months: $F_{(1,78)}=4.34, p<0.05 ; 12$ months of age: $F_{(1,93)}=4.5$, 


\section{Habituation to Novel Environment}
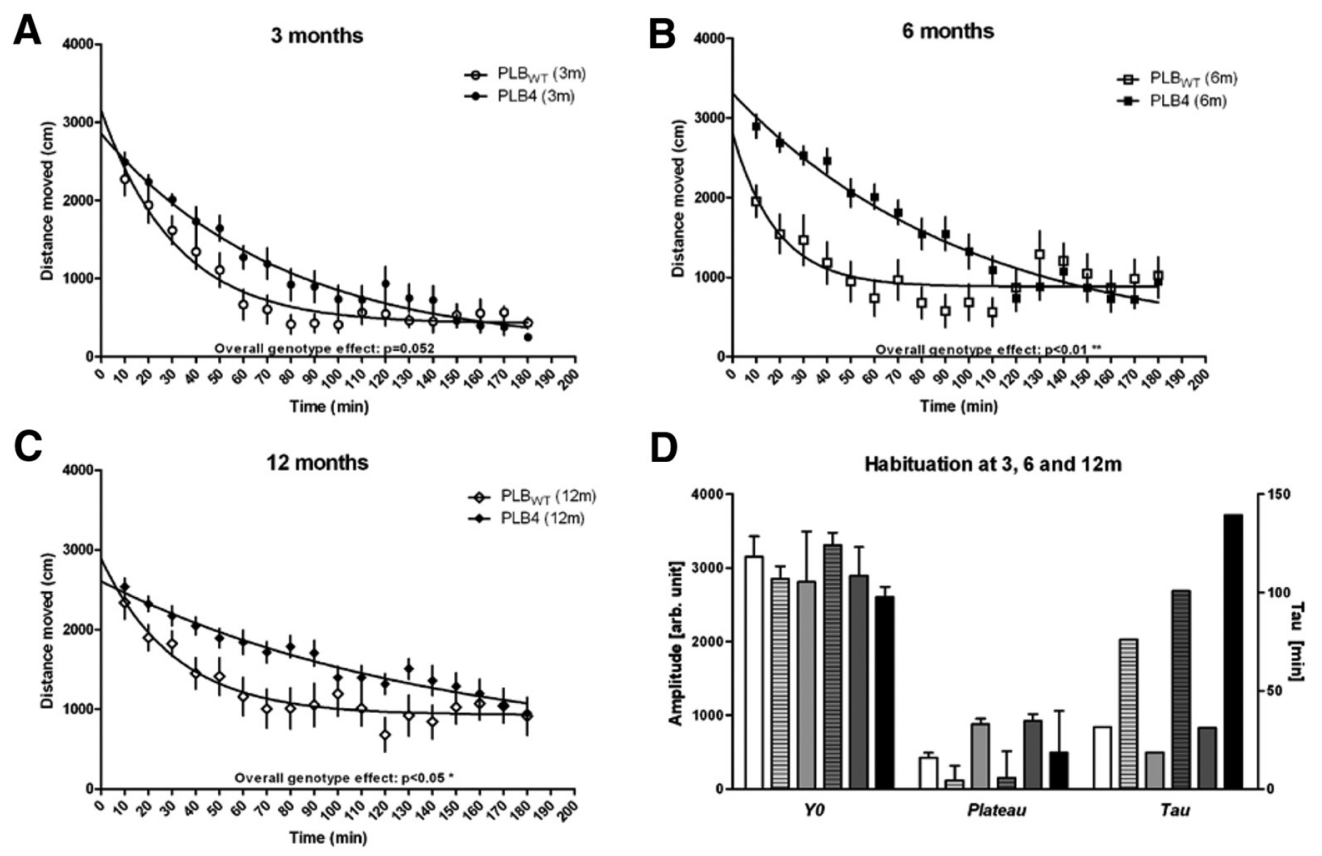

Activity in Habituated Animals
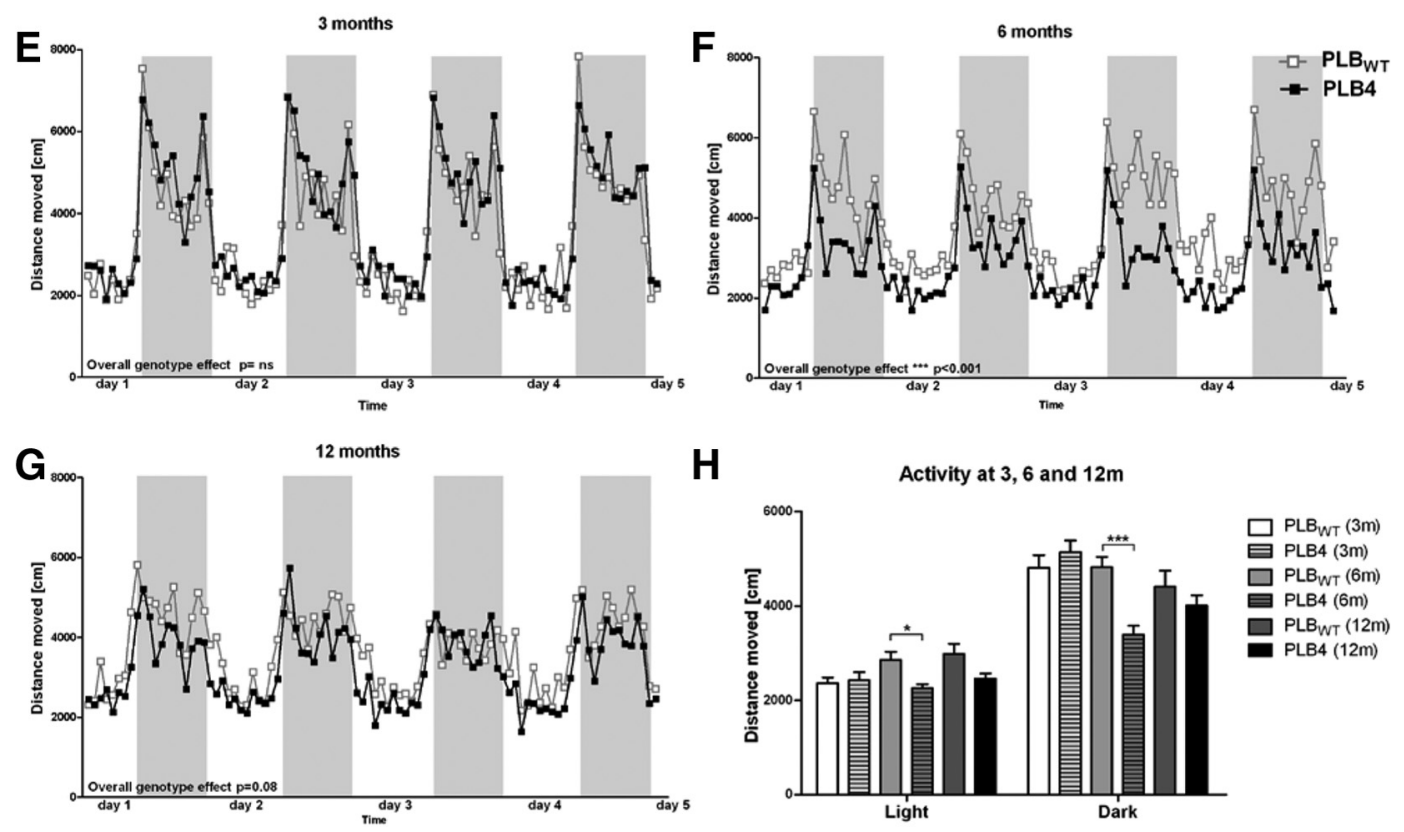

H

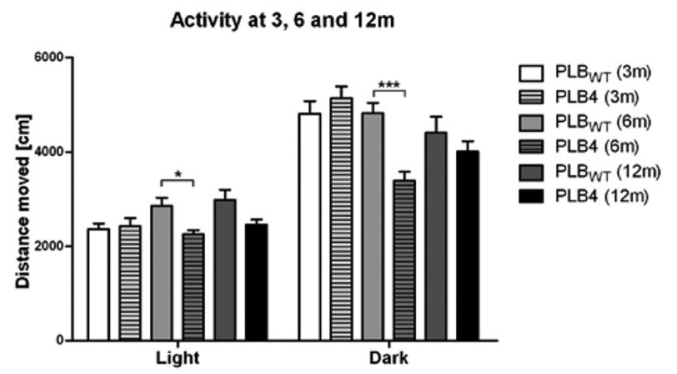

Figure 3. Habituation to a novel environment, locomotor activity, and circadian rhythms. $\boldsymbol{A}$, Nonlinear regression analyses of activity (distance moved, cm) during habituation to the PhenoTyper revealed strong trends for overall genotype effect in 3-month-old PLB4 mice compared with $\operatorname{PLB}_{\mathrm{WT}}(p=0.052)$, with transgenic animals exhibiting heightened exploration during the initial $3 \mathrm{~h}$ of habituation. Increased activity was also observed in 6- $(\boldsymbol{B})$ and 12-month-old (C) PLB4 animals compared with age-matched PLB wT $_{\text {mice }}(p<0.001$ and $p<0.05$, respectively). This noveltyinduced hyperactive phenotype of transgenic subjects yielded increased tau values compared with $P L B_{W T}$ mice, indicating heightened exploration and delayed habituation in a new environment. D, A robust aging effect on habitation activity was identified in PLB4 mice, whereas no similar trends were noted for controls. $\boldsymbol{E}-\boldsymbol{G}$, Distance moved ( $\mathrm{cm}$ ) in hourly bins over $96 \mathrm{~h}$ (posthabituation) was unaltered in PLB4 animals at 3 months, but markedly affected from 6 months onward. $\boldsymbol{H}$, Mean distance moved (+SEM) pooled for light and dark phases were decreased at 6 and 12 months, respectively; ${ }^{*} p<0.05,{ }^{* * *} p<0.001$. Data are shown as means \pm SEM.

$p<0.05$; Figure $6 A$ and $B$, respectively). No effect of age was uncovered for either genotype $(F<1)$. Planned post hoc analyses for the performance on the last day suggested that 6-month-old PLB4 mice did not reach the same level of performance compared with age-matched $\mathrm{PLB}_{\mathrm{WT}}$ mice $(p<0.05)$. This also resulted in a genotype effect uncovered for the probe trial, where the younger age group spent less time in the target quadrant (overall genotype effect: two-way ANOVA with genotype and age as factors: $F_{(1,58)}$ $=4.5, p<0.05$; Fig. $6 D$; time in the target quadrant at 6 months: $p<0.05$ ). Additionally, even though all groups remained above chance in the correct quadrant (Wilcoxon signed rank test, all $p<0.05)$, PLB4 mice were significantly impaired compared with PLB $_{\mathrm{WT}}$ at 6 months $(p<0.05)$. Close inspection of probe trial data suggested a trend for an age-related decline in $\mathrm{PLB}_{\mathrm{WT}}$ per- 
A

LDB

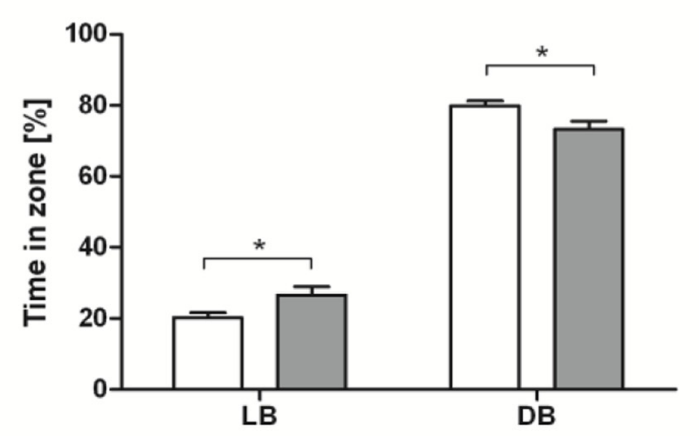

C LDB and EPM
Distance moved

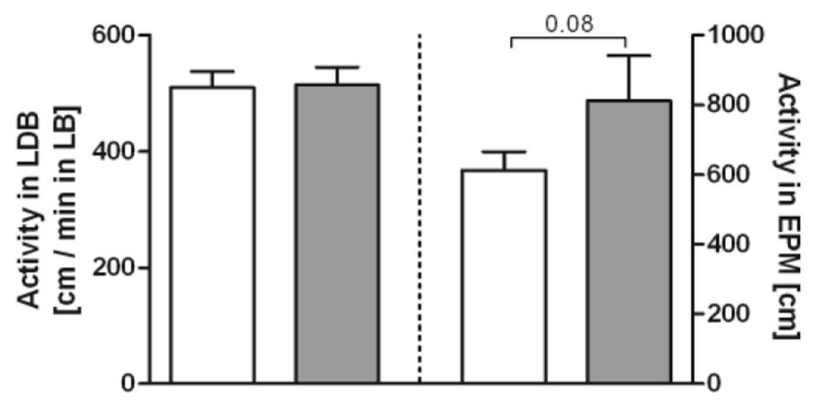

B

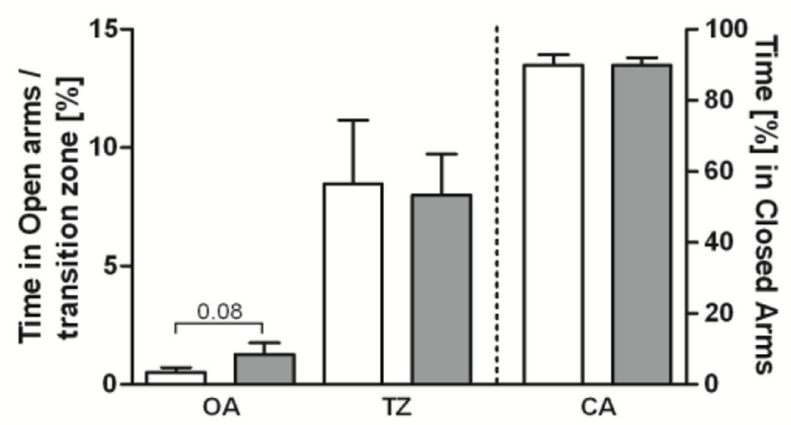

D

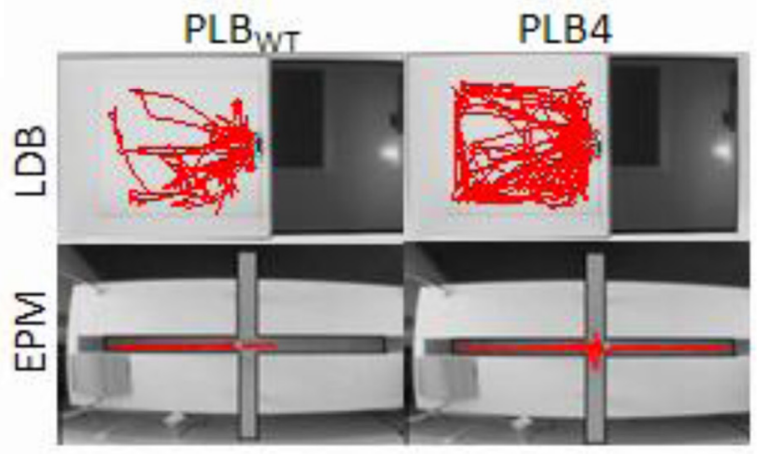

Figure 4. Anxiety-related behaviors in the LDB and EPM. $A$, Although the LDB was anxiogenic for both genotypes, transgenic animals exhibited increased time in the light box (LB) and reduced time in the dark 'safe' compartment (dark box, DB) compared with controls. $\boldsymbol{B}$, A similar trend was observed for time spent in open arms (OA) of the EPM $(p=0.08)$, where PLB4 mice were less anxious than PLB ${ }_{W T}$ subjects (TZ, transition zone; CA, closed arms). C, Evidence for increased locomotor activity of transgenic animals was observed in the EPM ( $p=0.08$ ), but not in the LDB (note, distance moved was normalized to total time in LB). $\boldsymbol{D}$, Representative activity traces from both paradigms. Data are expressed as mean $+\mathrm{SEM} ;{ }^{*} p<0.05$.

A

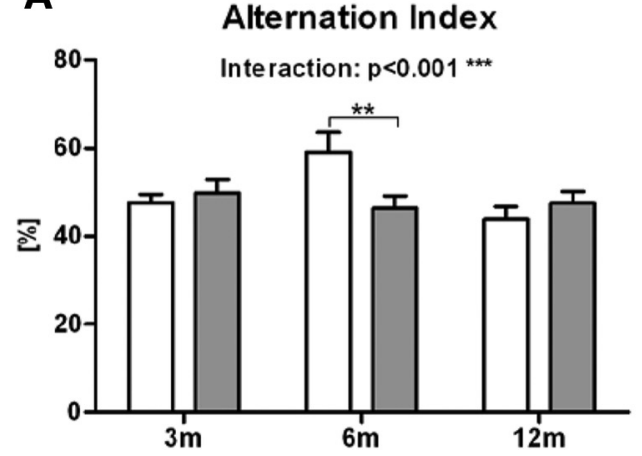

B

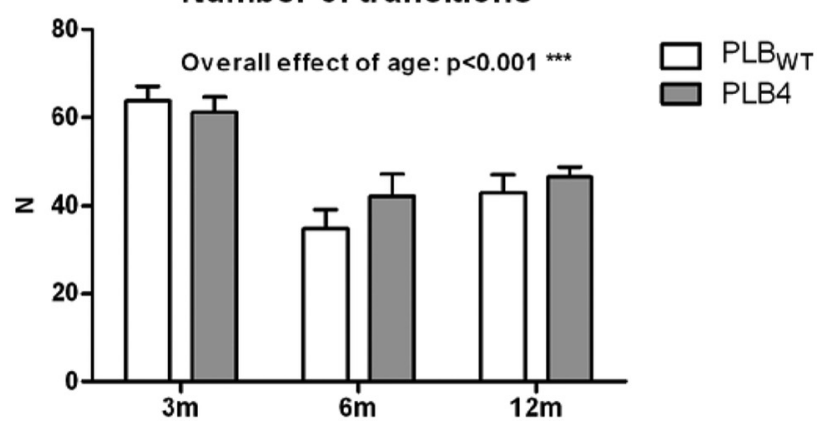

Figure 5. Spatial working memory and spontaneous alternations of $\mathrm{PLB}_{\mathrm{WT}}$ and PLB4 animals at 3, 6, and 12 months of age in $Y$-maze. $\boldsymbol{A}$, Correct alternations (in \%) were reduced compared with $\mathrm{PLB}_{\mathrm{WT}}$ mice at 6 months of age (-13\%) only. $\boldsymbol{B}, 0$ verall effect of age, but not genotype, was identified for total number of transitions made, with 3-month-old animals being more exploratory. Data represent means + SEM; ${ }^{* *} p<0.01$.

formance (one-tailed $t$ test, $p=0.09$ ), whereas PLB4 mice remained at a constant level matching that of 12-month-old PLB $_{\text {WT }}$.

Activity analysis revealed normal swim speeds in 6-month-old transgenic animals but, in contrast to control subjects, no agedependent reduction in swim speed was observed in PLB4 mice, resulting in a significant age effects in $\operatorname{PLB}_{\mathrm{WT}}$ only $\left(F_{(1,78)}=32.5\right.$; $p<0.001)$ as well as a significantly enhanced swim speed in 12-month-old PLB4 compared with age-matched controls $\left(F_{(1,93)}=21.54, p<0.001\right.$; Fig. $\left.6 C\right)$.
A richer understanding of the behavioral anomalies expressed by PLB4 mice was obtained by categorization of each trial into specific swim patterns (Fig. 7). Examples of categories are displayed in Figure $7 \mathrm{~A}$ with matched color coding, i.e., cold colors indicate more spatial and warm colors more nonspatial strategies. What is evident from the relative occurrence of each category is the natural progression in all cohorts from $\sim 15 \%$ spatially oriented swims on day 1 to $>40 \%$ on day 4 , whereas nonspatial strategies declined by the same amount (Fig. 7B-E). PLB4 mice differed reliably from controls on each day at both 6 and 12 months (except day 2 at 12 months; see statistical 
A

$$
\text { Acquisition (6 months) }
$$
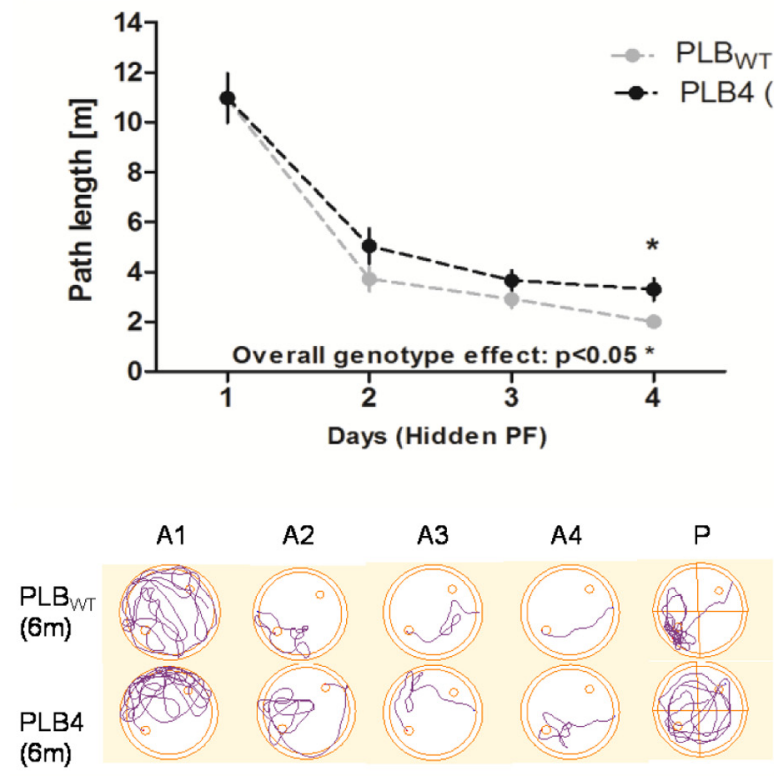

B

\section{Acquisition (12 months)}
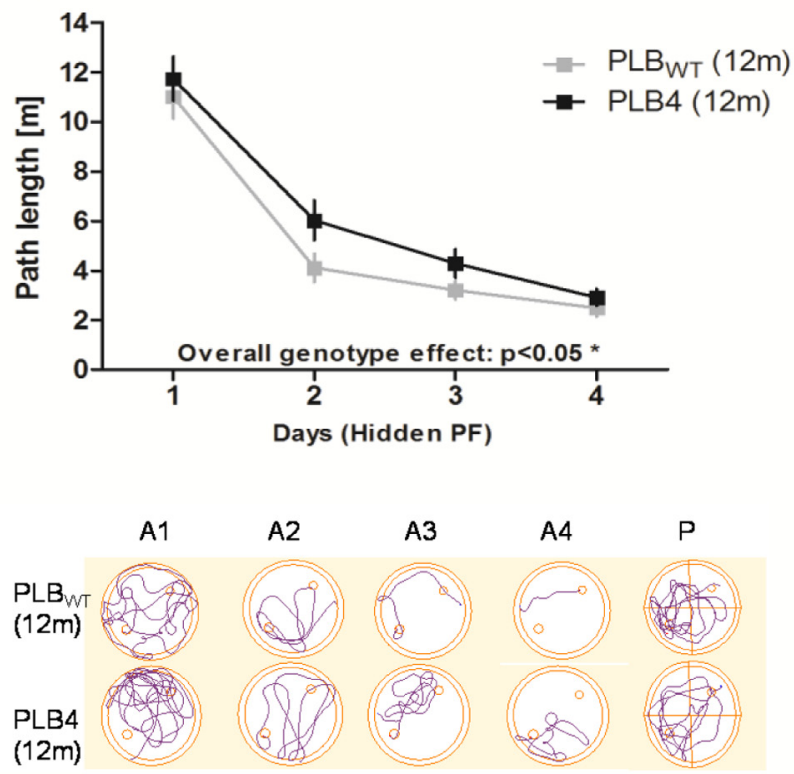

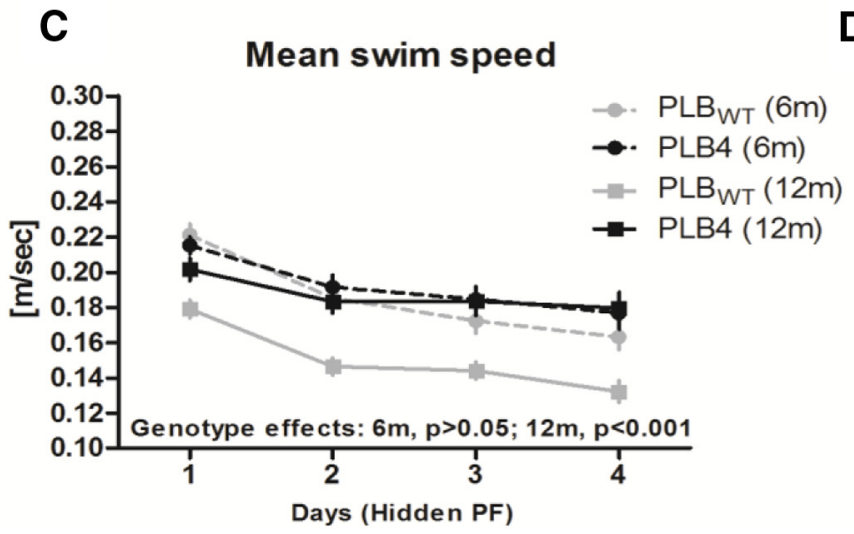

D

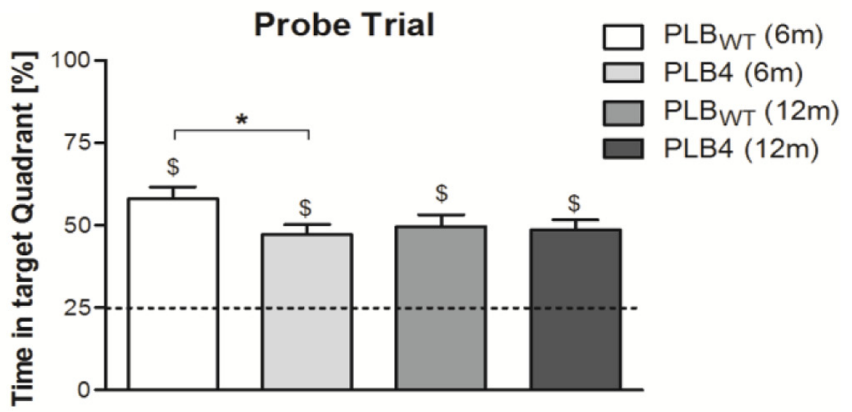

Figure 6. Spatial memory of PLB $B_{W T}$ and PLB4 animals at 6 and 12 months of age in the water maze. $A, B$, Mean path length for each day of testing and representative swim paths for acquisition days and probe trial (A1-A4 with hidden platform; P: probe trial). PLB4 animals presented with a learning impairment during acquisition days at both 6 and 12 months of age. $C$, PLB $B_{W T}$ controls showed an age-induced reduction in swim speed; PLB4 animals continued to swim with high velocity at 12 months of age. $\boldsymbol{D}$, Performance in the probe trial revealed an overall genotype effect, and was significantly affected in 6-month-old group. Data are expressed as means $\pm \mathrm{SEM} ;{ }^{*} p<0.05,{ }^{* *} p<0.01$.

summary in Fig. 7), caused largely by fewer directed swims ( 50\% reduced cf. WT) and a modest lowering of focal searches in the PLB4 groups. At the same time, PLB4 mice were slower to abstain from wall hugging and maintained scanning $(>10 \%)$ and ultimately very high percentage of chaining responses $(\sim 35 \%)$ to solve the task (WT: 7 and 20\%, respectively). This difference was observed at both ages and suggests a spatial impairment already present at 6 months. One possibility, however, is that path efficiency $(E)$ within each exclusive category may differ between genotypes (and ages) so that random searches may be less efficient in PLB4 mice than in PLB ${ }_{\mathrm{WT}}$. However, respective data summarized in Table 1 reveal that path efficiency was equal in all cohorts for each trial category. From these values, an obvious conclusion is that the modestly enhanced chaining strategy over directed search or focal strategies produces a small loss of 10-15\% path efficiency; this can fully account for the spatial learning deficit observed in both PLB4 cohorts (Fig. 6A,B).

Long-and short-term semantic-like memory deficits follow different time courses

Further characterization of cognitive phenotypes used the semantic-like STFP task at 4 and 6 months of age (Fig. 8). Before this task, olfactory function of transgenic animals was assessed using the "Buried Cookie Test" (adapted from Yang and Crawley, 2009), in which hBACE1 mice exhibited normal latencies to a hidden olfactory cue compared with control mice indicating intact olfactory abilities (data not shown).

During the social interaction phase of STFP (30 min), we detected no difference between any of the groups with regards to their social interest in the demonstrator mouse (time in social interaction zone, two-way ANOVA: $\left.F_{(1,72)}=1.9 ; p>0.05\right)$, and all groups spent an average of $\sim 10 \mathrm{~min}$ with the demonstrator $(p>0.05$; data not shown), indicating absence of anxiety as well as normal exploratory and social responsiveness.

During the food preference test, 4-month-old transgenic animals exhibited intact memory for the cued (presented) food in the short-term test (15 min delay, STM) as indicated by a food preference $\left(72.5 \%\right.$ in PLB4 vs $82.8 \%$ in $\mathrm{PLB}_{\mathrm{WT}}$ ) significantly above the level of chance $(p<0.01)$. Interestingly, their residual LTM for correct food did not differ from the level of chance (55\%, $p=0.36$; Fig. 8A). Hence, PLB4 mice displayed a delaydependent disruption in memory retrieval at 4 months. Results 
A
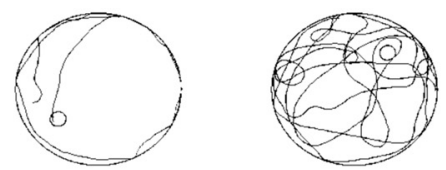

Wall hugging

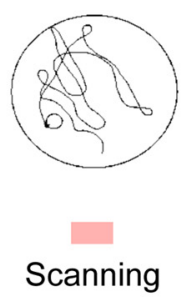

Random
B

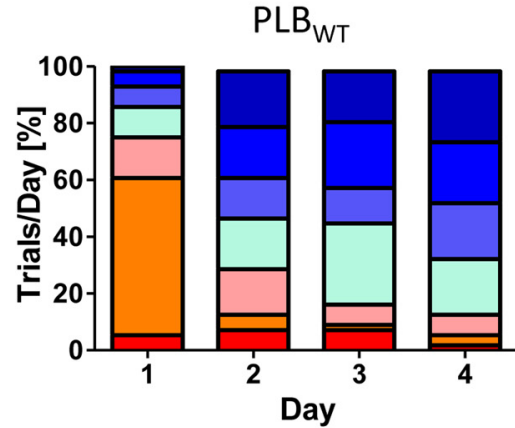

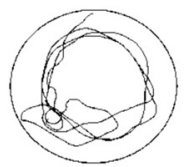

Chaining
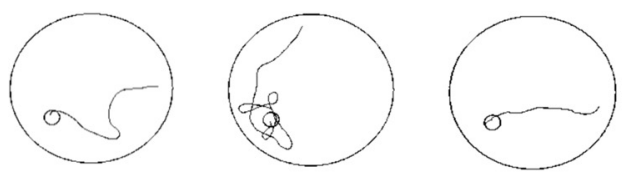

Directed search

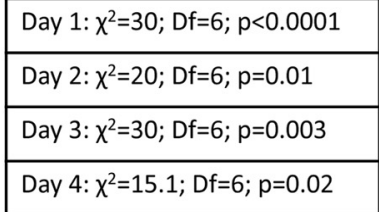

C

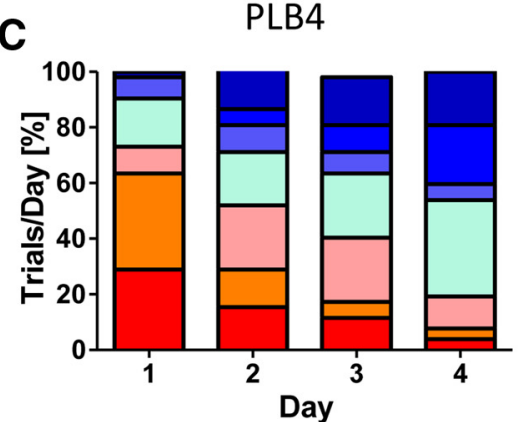

\begin{tabular}{|l|}
\hline Day $1: \chi^{2}=20 ; D f=6 ; p=0.0006$ \\
\hline Day $2: \chi^{2}=7 ; D f=6 ; p=0.35$ \\
Day 3: $\chi^{2}=20 ; D f=6 ; p=0.004$ \\
Day $4: \chi^{2}=23.3 ; D f=6 ; p=0.0007$ \\
\hline
\end{tabular}

E

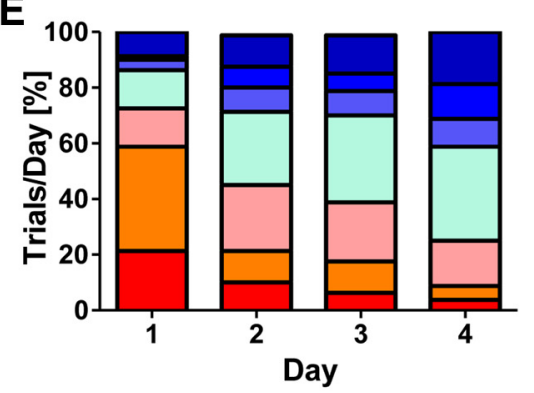

Figure 7. Strategy analysis of water maze performance in PLB4 and PLB $B_{W T}$ cohorts revealed striking genotype differences. $A$, Representative sample traces of identified swim categories and their color codes. Mean relative occurrence of each strategy is presented for the four spatial acquisition days for PLB $\mathrm{WT}_{\mathrm{WT}}$ aged $6(\boldsymbol{B})$ and 12 (D) months, as well as respective PLB4 cohorts (C, E). Data tables display reliable genotype differences based on the statistical comparison of contingency plots between age-matched cohorts, with $\alpha$ set to $5 \%$.

Table 1. Path efficiency categorized by strategy choice

\begin{tabular}{|c|c|c|c|c|c|c|c|c|c|}
\hline & \multicolumn{2}{|c|}{$\mathrm{PLB}_{\mathrm{WT}} 6 \mathrm{~m}$} & \multicolumn{2}{|c|}{$\mathrm{PLB}_{\mathrm{WT}} 12 \mathrm{~m}$} & \multicolumn{2}{|c|}{ PLB46 m } & \multicolumn{2}{|c|}{ PLB4 $12 \mathrm{~m}$} & \multirow[b]{2}{*}{ ANOVA } \\
\hline & Mean & SEM & Mean & SEM & Mean & SEM & Mean & SEM & \\
\hline Direct & 90.2 & 1.4 & 87.9 & 3.8 & 92.7 & 1.8 & 90.5 & 2.5 & $F<1, p=0.69$ \\
\hline Focal & 42.2 & 3 & 42.3 & 3.5 & 51.1 & 4.6 & 47.7 & 5.2 & $F=1, p=0.36$ \\
\hline Directed & 53.9 & 2.5 & 49.6 & 3.7 & 50.1 & 4.4 & 51.5 & 3.4 & $F<1, p=0.80$ \\
\hline Chaining & 38.5 & 4 & 38.8 & 4.1 & 34.2 & 3.4 & 33.9 & 2.5 & $F<1, p=0.61$ \\
\hline Scanning & 29.2 & 4.3 & 21.3 & 2.7 & 29.6 & 4.1 & 28.8 & 2.7 & $F=1.3, p=0.29$ \\
\hline Random & 11.5 & 3.2 & 15.7 & 3.5 & 16.9 & 4 & 11.3 & 2.4 & $F<1, p=0.53$ \\
\hline Wall hugging & 24.2 & 4 & 15.8 & $2.4^{a}$ & 22.6 & 3.3 & 17.6 & 4.3 & $F<1, p=0.43$ \\
\hline
\end{tabular}

Overall, there was no difference between path efficiency within a given strategic category between genotypes, calculated as $E=$ (hypothetical perfect path / total recorded path) $\times 100$ yielding values between 100 (perfect trial) and 0 (platform not found). m, Months.

${ }^{a}$ Reliable age effect for PLB ${ }_{\mathrm{WT}}$ (one-tailed $t$ test).

were further supported by food consumed during the preference test (Fig. $8 B$ ), as PLB4 mice ate more cued compared with the novel food choice in the immediate test $(p<0.05)$, but lacked such a preference in the LTM test $(p=0.3)$. Additionally, frequency of visits to the jar zone appeared as an additional readout for this phenotype (Fig. 8C; STM: $p=0.055$; LTM: $p>0.05$ ).

At 6 months of age, an overall genotype difference was confirmed (for food preference in \%), with PLB4 displaying delayindependent deficits $\left(F_{(1,83)}=7.57, p<0.01\right.$; Fig. $\left.8 D\right)$. Preference scores of 55\% (STM test) and 66\% (LTM test) were obtained, both of which were significantly lower compared with PLB $_{\mathrm{WT}}$ (STM: $75 \%$ preference, $p<0.05$; LTM test: $88.5 \%$ pref- erence, $p<0.05$ ) and did not differ from the level of chance. Food intake data also suggested that PLB4 mice failed to reliably increase the intake of cued compared with novel food in the immediate test, whereas $\mathrm{PLB}_{\mathrm{WT}}$ displayed a significant preference (WT: $p<0.05$; PLB4 $p=0.06$; Fig. $8 E$ ). Similarly, for the $24 \mathrm{~h}$ delay, PLB4 mice failed to display intact residual memory for cued food (WT: $p<0.001$, PLB4: $p=0.09$ ). Again, food intake and frequency of visits confirmed food preference scores (Fig. 8E,F). With regard to total food intake, an age effect was detected in both genotypes (reduced consumption at 6 months cf. 4 months; $p<0.001$ ), and food intake was reduced in PLB4 mice over the LTM phase $(p<0.01)$. Although reduced food intake in PLB4 
A

\section{4 months}

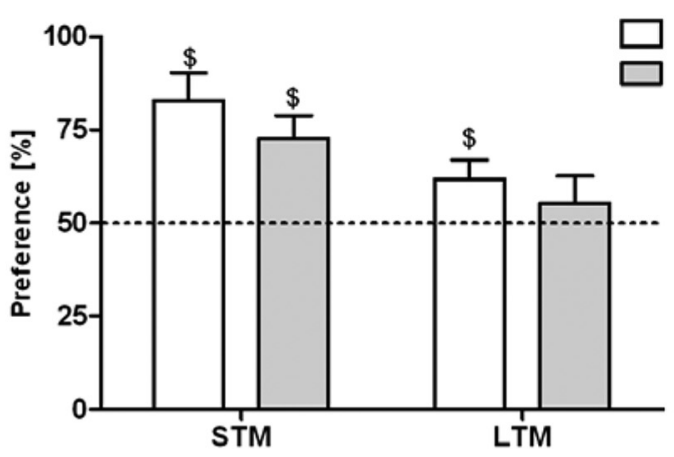

B

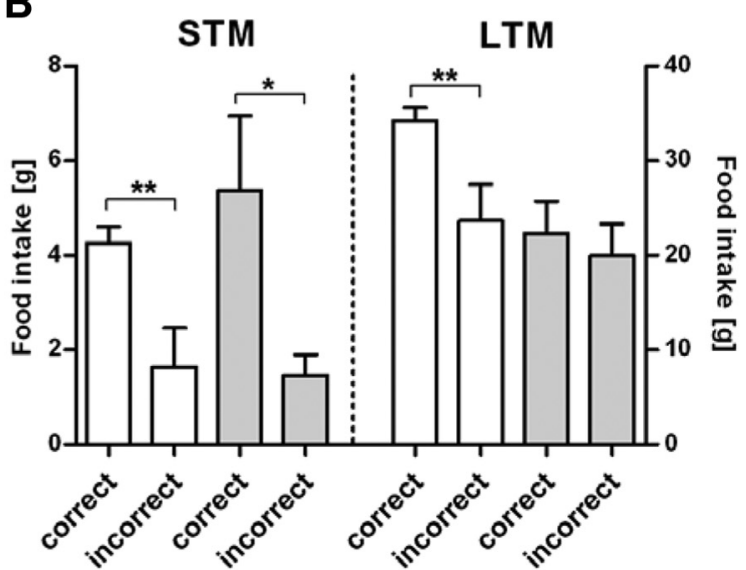

C

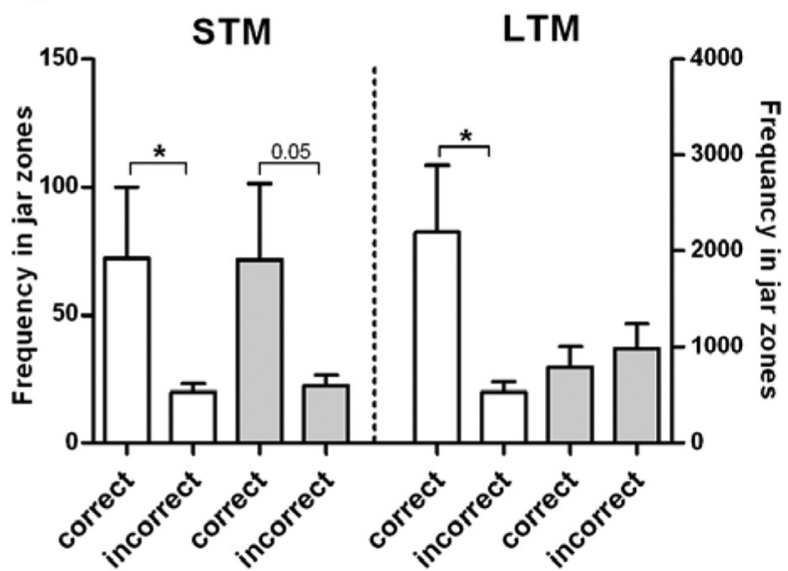

D

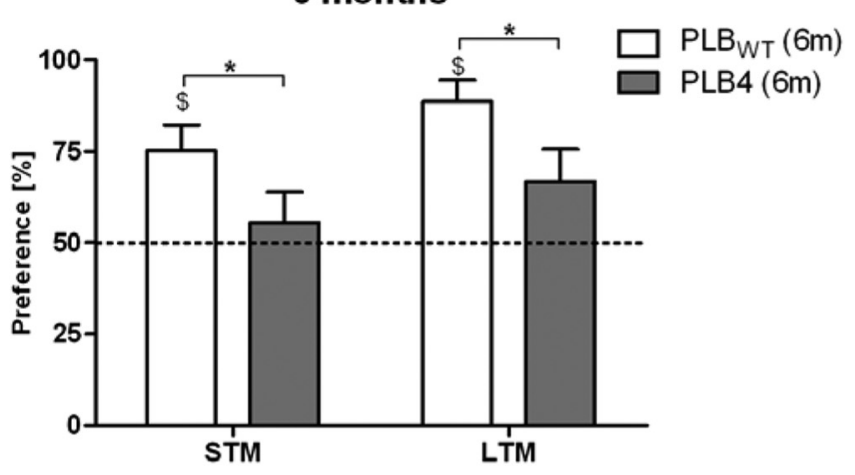

E

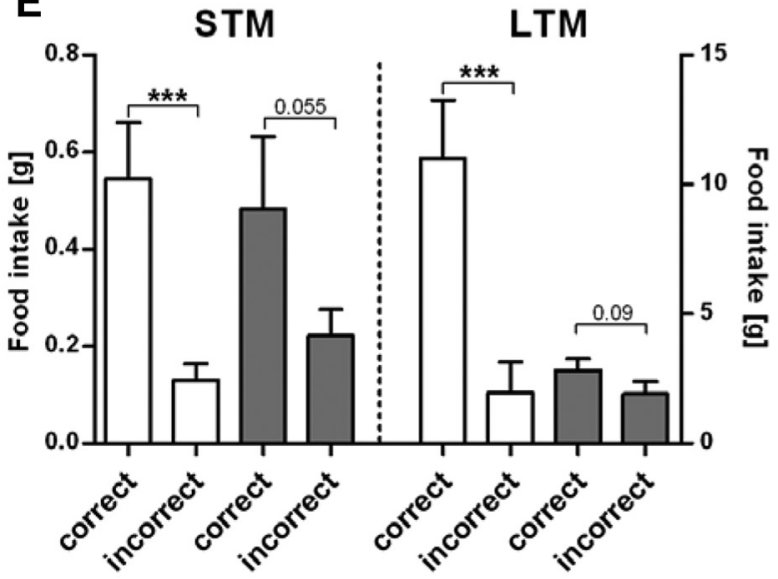

$\mathbf{F}$

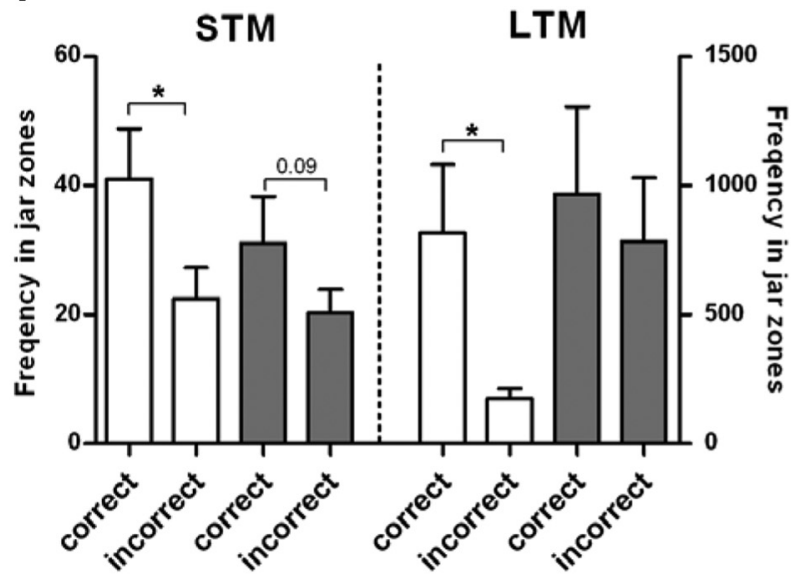

Figure 8. STFP test: semantic-like memory of PLB ${ }_{W T}$ and PLB4 animals at 4 and 6 months of age. $A$, Preference for cued food (in \%) in 4-month-old transgenic animals was intact in the STM test but affected in the LTM component, results did not differ from the level of chance; 50\%). B, C, Amount of cued food eaten and analysis of time spent in jar zones confirmed intact semantic-like STM and disrupted LTM in young transgenic animals. D, At 6 month of age the memory for cued food was significantly altered in PLB4 mice (with both STM and LTM scores not different to chance), with reduced preference in both delays compared with $\mathrm{PLB}_{\mathrm{WT}}$, indicating an age-dependent reduction in semantic-like retrieval. $\boldsymbol{E}, \boldsymbol{F}$, Analysis of raw food intake data and frequency of entry into jar zones during STM and LTM tests confirmed that only PLB $\mathrm{WT}_{\mathrm{W}}$ displayed intact memory for cued food. Data are expressed as means + SEM; $\$$, Indicates significantly above chance $(50 \%) ;{ }^{*} p<0.05,{ }^{* *} p<$ $0.01,{ }^{* * *} p<0.001$.

mice during the STFP may reflect decreased motivation to perform the test, further analysis indicated that the performance level in the STFP task did not correlate with food intake, and thus we can be confident that data expressed as preference score (in percentage) are genuine reflection of STM and LTM.

Overall, our STFP data suggest an age-dependent deficit in semantic-like memory in PLB4 animals, with long term retrieval being affected earlier than short term recall.
Tissue analyses: recruitment of mAPP by hBACE1 and resulting histopathologies

$A P P$ and $\beta$-amyloid pathology

To identify and quantify AD-relevant molecular changes that may underlie the behavioral phenotypes, and to characterize the impact of hBACE1 expression on endogenous mouse APP metabolism, Western blots were performed using whole brain soluble proteins from 6- and 12-month-old mice (Fig. 9A,B). The 
anti-mouse APP antibody recognized proteins at molecular weights of $\sim 115$ $\mathrm{kDa}, 50-56 \mathrm{kDa}, 17 \mathrm{kDa}$, and $10 \mathrm{kDa}$, corresponding to full-length $\mathrm{APP}, 56 \mathrm{kDa}$ oligomeric APP deposits (hereafter named *56 A $\beta$; Lesné et al., 2006, 2013), CTF- $\beta$, and CTF- $\alpha$ membrane-retained fragments, respectively. The antibody did not detect quantifiable bands $<10 \mathrm{kDa}$ (i.e., monomeric $\beta$ A). Robust differences were observed for APP metabolites samples from 6-month-old $\mathrm{PLB}_{\mathrm{WT}}$ and PLB4 mice. Primarily, a substantial reduction of full-length APP was seen in PLB4 brains $\left(-29 \%\right.$ relative to $\mathrm{PLB}_{\mathrm{WT}}$ bands at 115 $\mathrm{kDa} ; p<0.05$; Fig. 9 C), and a concurrent increase in accumulation of lower molecular weight APP fragments in young PLB4 subjects compared with age-matched PL$\mathrm{B}_{\mathrm{WT}}$ mice, indicating an accelerated proteolysis of endogenous APP in our transgenic mice. Specifically, accumulation of dodecameric ${ }^{*} 56 \mathrm{~A} \beta$ (double 9-12-mer band) was elevated in PLB4 brain supernatants compared with PLB $_{\mathrm{WT}}$ ( $+68 \%$ relative to age-matched controls, $p<0.05)$. Expression of the $17 \mathrm{kDa}$ CTF- $\beta$ fragment, a direct product of BACE1 cleavage, was also prominently increased in PLB4 forebrains $(+180 \%, p<$ 0.001 cf. $\left.\mathrm{PLB}_{\mathrm{WT}}\right)$. Intriguingly, 4 of 5 brain lysates from 6-month-old PLB4 mice displayed heightened production of neuroprotective CTF- $\alpha$ compared with agematched control brains (overall $p<0.05$; $10 \mathrm{kDa}$ band).

Analysis of 12-month PLB4 tissue using the murine-specific anti-APP/A $\beta$ antibody (Fig. 9D) also confirmed accelerated proteolysis of endogenous APP in aged PLB4 brains $(-21 \% \mathrm{cf}$. controls; $p<0.05)$, as well as elevated accumulation of $\mathrm{A} \beta^{\star} 56(+62 \%$ relative to aged WT; $p<$ $0.05)$ and trends for increased production of CTF- $\beta(+37 \% \mathrm{cf}$. $\mathrm{WT} ; p=0.08)$. Unlike younger transgenic mice, 12 -month-old PLB4 brains did not present with elevated levels of CTF- $\alpha$ compared with controls $(p>0.05)$. Analysis of relative $\mathrm{mAPP} / \mathrm{me}-$ tabolite composition (Fig. 9E) visualizes the pathological processing of the endogenous protein in hBACE1 mice independently of age, with 62 and 59\% of mAPP available as full-length APP in young and old PLB4 brains compared with 75 and $70 \%$ in controls, respectively, while depositing a substantial amount of toxic CTF- $\beta$ fragments and oligomeric ${ }^{*} 56 \beta$ A compared with age-matched $\mathrm{PLB}_{\mathrm{WT}}$ (6 m: 25 vs $13 \%$ in WT; $12 \mathrm{~m}: 30$ vs $20 \%$ in WT).

Two additional antibodies were used to determine the oligomeric $\mathrm{A} \beta$ profile in hBACE1 mice ( $6 \mathrm{E} 10$ and $\mathrm{MOAB}-2)$ and allow for a comparison with $\mathrm{PLB} 1_{\text {Triple }}$ mice. Both antibodies detected bands at 56, 27, and $12 \mathrm{kDa}$ (Fig. $10 A, B$ ), corresponding to $\mathrm{A} \beta{ }^{\star} 56$, hexameric and trimeric $\mathrm{A} \beta$ (Lesné et al., 2006). Quantification of bands validated heightened production of $A \beta^{\star} 56$ in symptomatic hBACE1 mice $(\sim 2$-fold increase, $p<0.05)$, and further revealed an increased accumulation of hexameric $A \beta$ in PLB4 brains compared with controls (6E10-immunorecative
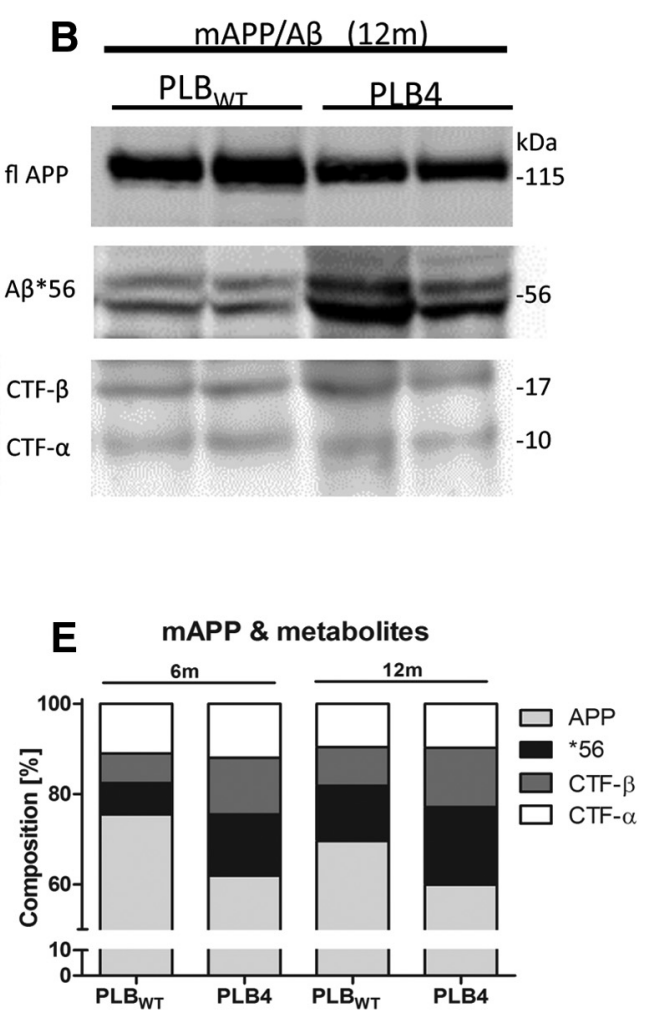

Figure 9. Molecular characterization of endogenous $A P P / A \beta$ profiles in PLB4 and control animals based on a rodent-specific ( 2 were only identified in 6-month-old hBACE1 soluble brain lysates compared with controls. $\boldsymbol{E}$, Composition

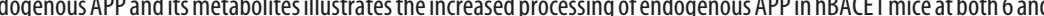
12 months of age, with reductions in APP amid increased accumulation of toxic higher order A $\beta^{*} 56$ oligomers and CTF- $\beta$ fragments. Data were Coomassie adjusted and represent means + SEM; ${ }^{*} p<0.05,{ }^{* * *} p<0.001$.

6-mer $\mathrm{A} \beta, p<0.05$; MOAB-2-immunoreactive 6-mer $\mathrm{A} \beta, p=$ 0.07 ; Fig. $9 C, D)$. Interestingly, $\mathrm{A} \beta$ pathology in hBACE1 animals was comparable to that of age-matched PLB1 $1_{\text {Triple }}$ mice compared with WT controls. Notably, monomeric A $\beta$ was not detected in the transgenic groups, and levels of $A \beta$ trimers were unaltered compared with PLB $\mathrm{WT}_{\mathrm{WT}}$. Further experiments were performed to validate the $56 \mathrm{kDa}$ fragment as genuine oligomeric assemblies of $\mathrm{A} \beta$, adapted from a previously verified HFIP disaggregation protocol (Lesné et al., 2006). Levels of ${ }^{\star} 56$ A $\beta$ in PLB4 brain lysates were concentration-dependently reduced upon HFIP application (0, 10, and 20\% were used) amid a concomitant increase in levels of monomeric amyloid peptide $(>4 \mathrm{kDa}$; Fig. $10 E)$. To determine whether monomeric $\mathrm{A} \beta$ accumulated in transgenic PLB brain tissue in the absence of depolymerizing agents, we also immunoprecipitated soluble brain factions from PLB4 and PLB1 $1_{\text {Triple }}$ mice with 6E10-conjugated dynabeads (Fig. $10 F)$. Immunoprecipitated samples from PLB4 and PLB1 $1_{\text {Triple }}$ mice presented with pronounced expression of bands corresponding to oligomeric $\mathrm{A} \beta$ species (12-meric ${ }^{\star} 56$, 6-mer, 4 -mer, and 3-mer) compared with $\mathrm{PLB}_{\mathrm{WT}}$ controls, whereas samples from an APP/PS1 overexpression model exhibited saturated signals for full-length APP and monomeric $\mathrm{A} \beta$, but no oligomeric 

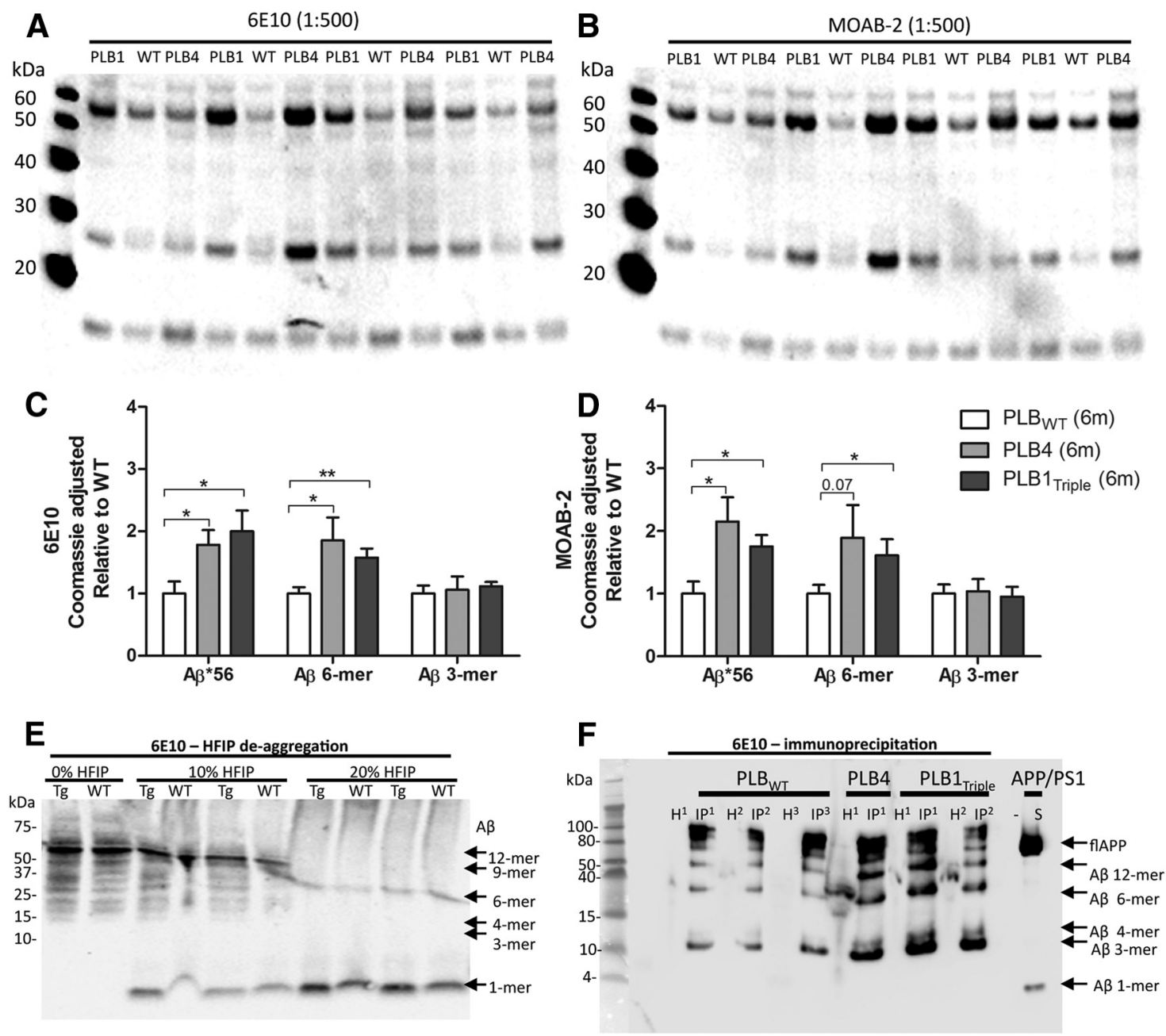

Figure 10. Detailed screening of oligomeric $A \beta$ in 6-month-old hBACE1 knock-in mice as well as a comparison with the targeted knock-in PLB1 $1_{\text {Triple }}$ mouse and a pronuclear injection-derived APP/PS1 mouse. $A, B$, Representative Western blots of soluble brain lysates from PLB ${ }_{W T}, P L B 4$, and PLB1 $1_{\text {Triple }}$ mice, stained with the $6 E 10(A)$ antibody and the oligomer-specific MOAB-2 antibody $(B)$, detecting $A \beta^{*} 56$, hexameric, and trimeric $A \beta$. C, D, Quantification of $6 E 10$ and MOAB-2 immunoreactivity validated the marked increases in $A \beta^{*} 56$ accumulation in PLB4 mice compared with $P L B_{W T}$ controls, and further uncovered the heightened occurrence of hexameric $A \beta(27 \mathrm{kDa})$. Trimeric $A \beta$ did not differ in $\mathrm{hBACE} 1 \mathrm{knock}$-in mice compared with WT at 6 months of age. Interestingly, the two PLB lines showed comparable levels of oligomeric species. E, HFIP-induced disaggregation of oligomeric A $\beta$ species in PLB4 brain lysates. Expression of dodecameric ${ }^{*} 56$ and lower molecular weight $A \beta$ assemblies including the monomeric form was HFIP concentration-dependent. $F, 6$ E10-IP brain lysates from PLB4 and PLB1 Triple mice exhibited pronounced expression of A $\beta^{*} 56,6$-mer, and 3-mer $A \beta$ compared with PLB ${ }_{w T}$ controls, whereas pronuclear injection-derived the APP/PS1 sample presented with bands corresponding to monomeric $A \beta$ and full-length APP (fIAPP) only. Monomeric $A \beta$ was not detected in transgenic PLB brain lysates even upon IP, suggesting that A $\beta$ favors an oligomeric state. H, Depleted homogenate; $S$, supernatant. All Western blot data were normalized to Coomassie and expressed relative to appropriate WT controls. Data represent means $+\mathrm{SEM} ;{ }^{*} p<0.05,{ }^{* *} p<0.01$.

species. These observations cumulatively suggest levels of monomeric $\mathrm{A} \beta$ in both PLB lines to be below the detection limit, likely due to a favored conversion to $\mathrm{A} \beta$ oligomers and overall contrasting with an APP overexpression model.

To further determine APP processing and regional A $\beta$ accumulation in PLB4 mouse brains, immunoreactivity was quantified in brain sections from 12-month-old animals. The anti-mouse APP antibody did not yield specific binding in histological sections, hence, the $6 \mathrm{E} 10$ antibody was used which showed specific staining due to cross reactivity with the highly homologous mouse amyloid sequence (Fig. 11A).

Significantly enhanced APP/amyloid somatic staining was observed in PLB4 tissue relative to WT's in both hippocampal areas (Fig. 11B, intracellular), i.e., PLB4 animals exhibited significantly more 6E10-positive cells in CA1 and DG compared with PLB ${ }_{\mathrm{WT}}$ (both $p<0.001$ ). Elevated extraneuronal accumulation was also evident in areas CA1 $(p<0.01)$ and DG $(p<0.05)$, alongside respective trends in cortex $(p=0.06)$. Consequently, only intra- cellular occurrence of $\mathrm{APP} / \mathrm{A} \beta$ showed some region-specificity, whereas extracellular amyloid accumulation was more broadly increased in aged PLB4 forebrains compared with controls.

Although pronounced APP/A $\beta$ accumulation surrounding neuronal somata was observed, 6E10-positive plaques were sparse $(<5-8$ per section, Fig. $11 C)$ and generally small. Nevertheless, prominent extracellular staining was also identified in other PLB4 forebrain areas, including neurons in fiber track ramifications (lower lateral corpus callosum; Fig. 11D), often surrounding cell bodies undergoing nuclear inclusions (Fig. 11E,F). Degenerated neurones with residual cytoplasmic constituents were rarely observed in WT tissue but prominent and frequent in transgenic brains (Fig. 11F).

Preliminary analyses of putative changes in tau or phopho-tau expression provided no reliable evidence for abnormal phosphorylation or conformational changes of endogenous tau in PLB4 mice, only trends were observed for an increase of total tau levels at 6 months of age (data not shown). 
A
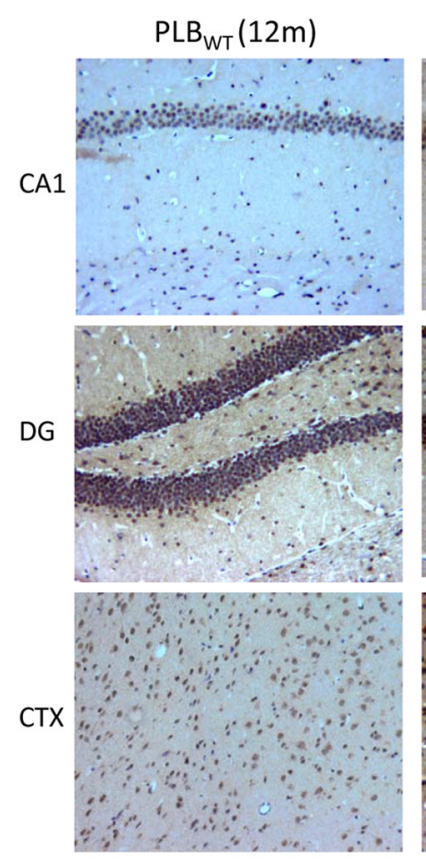
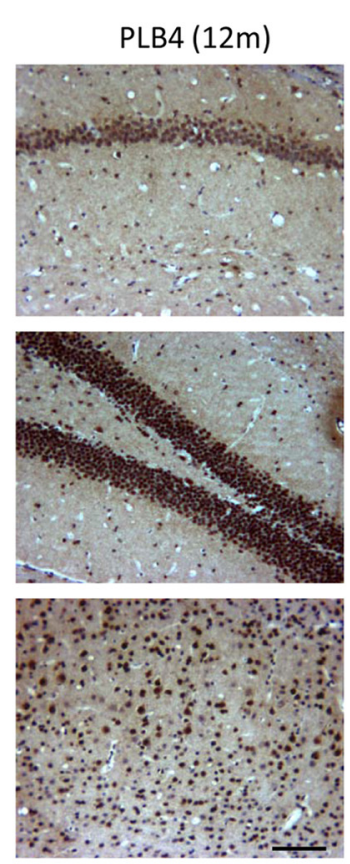

B
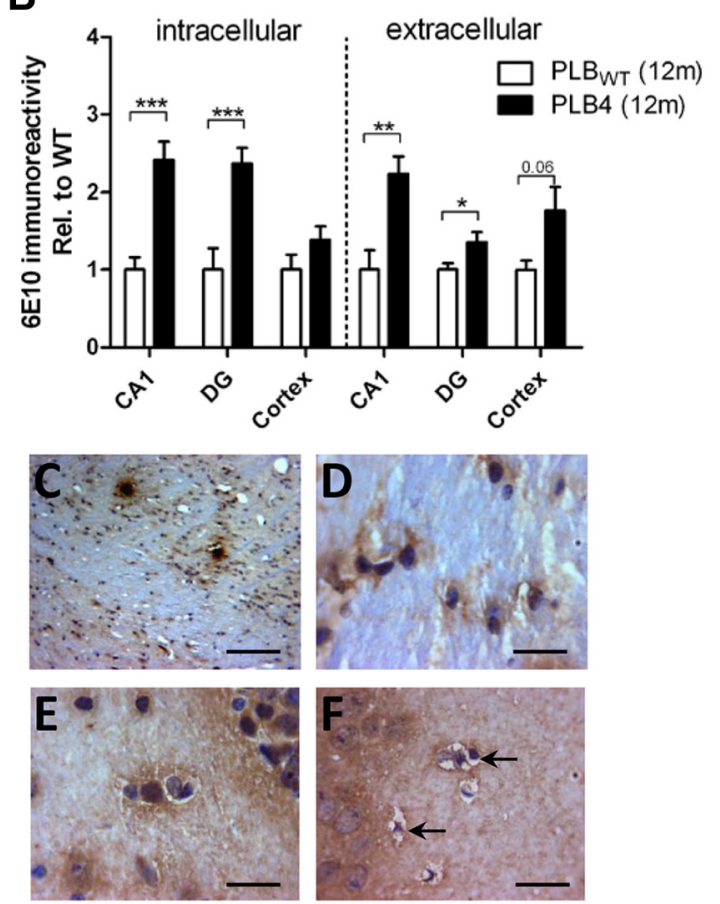

Figure 11. Immunocytochemical characterization of APP/A $\beta$ accumulation in 12-month-old PLB $\mathrm{WT}_{\mathrm{T}}$ and PLB4 brain tissue (6E10 staining). $A$, Representative histological images of accelerated amyloid pathology in brains of old mice overexpressing hBACE1 ( $n=4$ per group). Strong immunoreactivity to 6E10, associated with hippocampal (CA1 and DG) and cortical (CTX) neurones were found in PLB4 mice. The scale bar indicates $100 \mu \mathrm{m} . \boldsymbol{B}$, Quantification of intracellular and extracellular A $\beta$ accumulation revealed a significant increase in the brains of transgenic animals compared with control group. Data (means + SEM) were normalized to WT. PLB4 brain tissue exhibited infrequent amyloid plaques $(\boldsymbol{C}$, prominent intra- and extra-neuronal APP/A $\beta$ occurrence in fiber tracts $(\boldsymbol{D})$, and numerous neuronal inclusions in hippocampal areas $(\boldsymbol{E}, \boldsymbol{F})$. Scale bar: $\boldsymbol{C}, 400 \mu \mathrm{m} ; \boldsymbol{D}-\boldsymbol{F}, 40 \mu \mathrm{m}$. Asterisks show differences to controls; ${ }^{*} p<0.05,{ }^{* *} p<0.01$, ${ }^{* * *} p<0.001$.

\section{Gliosis and inflammation}

Additional histopathological changes were investigated with regards to putative astrocyte activation as a marker for inflammatory reactions due to hBACE1 knock-in and APP pathology at 12 months of age for several AD- and cognition-relevant brain areas. Accelerated inflammation was identified in PLB4 brain tissue (Fig. 12A, B), in a region-specific and genotype-dependent manner. Highest levels of astrogliosis were encountered within the DG $(p<0.001)$, but levels were also significantly higher in hippocampal CA1 $(p<0.05)$ and piriform cortex $(p<0.01$, Pir $)$, whereas only trends were observed within the parietal association area and amygdala ( $p=0.08$ and $p=0.09$, for PtA and Am, respectively).

Finally, we investigated whether levels of inflammation correlated with cognitive performance, i.e., by separating histological data from good and bad PLB4 learners (based on performance in the OFWM). Planned paired comparison indicated that WT mice differed substantially from bad learners due to differences in DG $(p<0.0001)$, $\operatorname{Pir}(p<0.001)$, and $\mathrm{Am}(p<0.01)$, whereas good learners differed significantly only in the DG $(p<0.001)$. Comparing good and bad learners within the PLB4 cohorts further corroborated the link between inflammation and learning performance (two-way ANOVA, performance and brain area as factors; $F_{(1,55)}=13.82, p<0.001$; Fig. $\left.12 C\right)$, with bad learners exhibiting substantially stronger GFAP staining compared with good learners; both parietal association cortex (PtA, $p<0.001)$ and CA1 $(p<0.05)$ displayed significantly more inflammation in bad learners compared with good learners. Hence, DG inflammation common to both groups did not contribute to the learning phenotype.

\section{Discussion}

BACE1 activity is recognized as the rate limiting step in the pathological processing of APP (Ahmed et al., 2010) and several attempts have been made to characterize its function in vivo. To date, results from four mouse models overexpressing hbacel, all generated via pronuclear injection techniques, have been reported. These were primarily designed to create app $\times$ bacel double-transgenic lines, AD-relevant behavioral phenotypes and underlying cellular changes were not assessed in detail. The first line (overexpression 4- to 10fold cf. wild types) was developed by Harrison et al. (2003), who characterized basic behaviors (SHIRPA screen) and neurochemical changes (BACE expression and CTFs), but phenotypic assessments did not investigate $\mathrm{AD}$-relevant behaviors and biochemical markers. Similarly, other models generated via pronuclear injection reported accelerated APP processing based on CTF analyses (Bodendorf et al., 2002) and increased amyloid deposition when crossed with appexpressing mice (Chiocco et al., 2004; Mohajeri et al., 2004), thus demonstrating that coexpression of hBACE1 significantly exacerbates hAPP processing and $\mathrm{A} \beta$ production. Together, these reports did not establish hBACE1 actions in the absence of human APP, and whether this is sufficient to induce amyloidosis and AD-related phenotypes in mice.

Here, we report that knock-in and subtle expression of hbacel led to a compelling age- and task-dependent phenotype in the absence of hAPP (over)expression, resembling many aspects of human AD. Southern blots, Western blots, and immunohistochemical analyses confirmed hBACE1 expression profiles, with approximately twofold protein levels compared with endogenous mouse BACE1; BACE1-positve neurones were particularly frequent in cortical and hippocampal areas. 
A
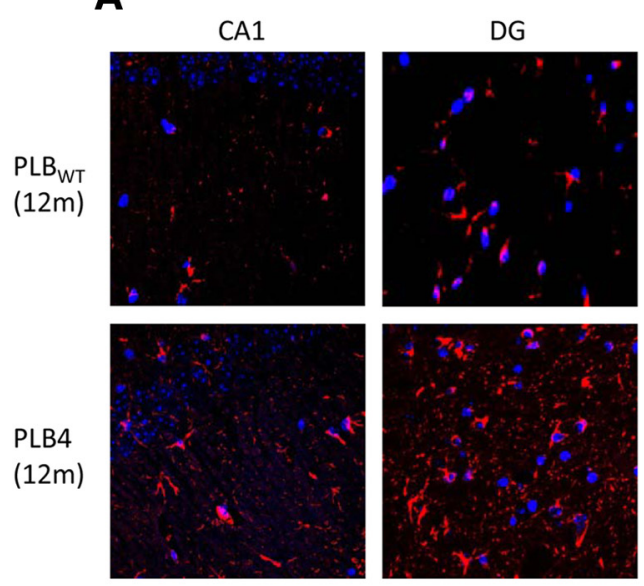

B

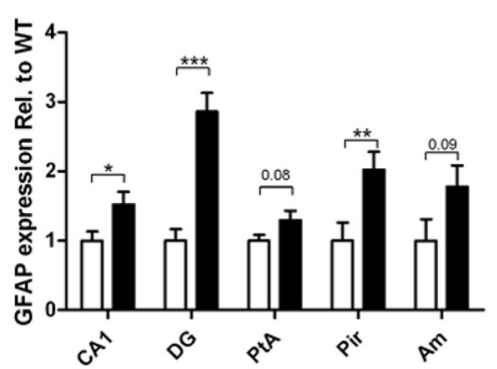

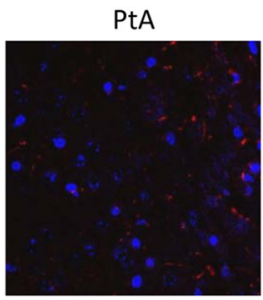
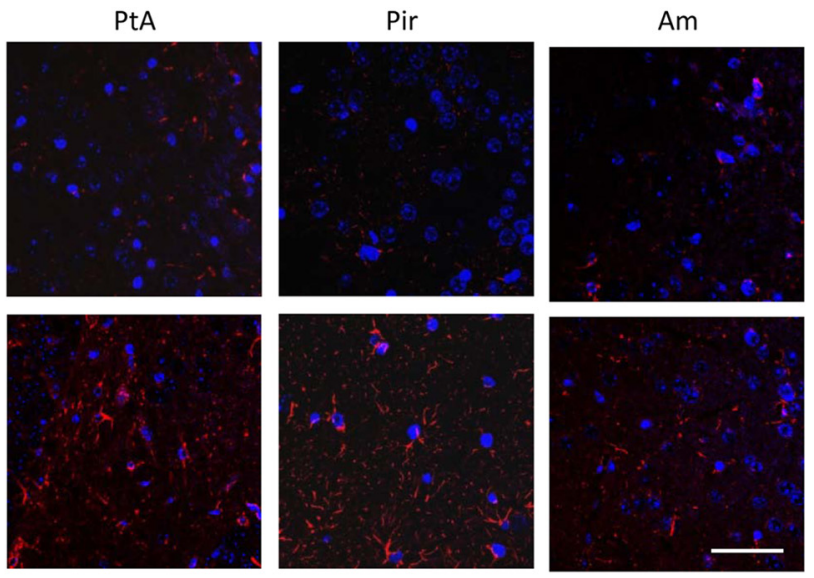

C

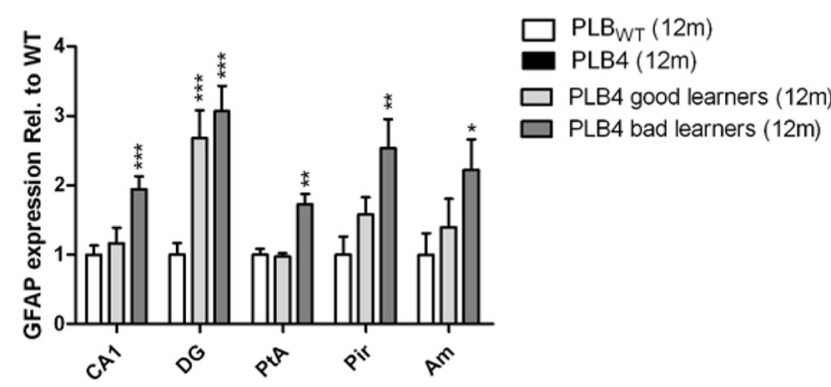

Figure 12. Regional expression and quantification of GFAP-labeled astrocytic cells at 12 months of age. $A$, Representative confocal images of active astrocytes (red) in subcortical (CA1, DG, Am) and cortical areas (PtA, Pir) from WT and PLB4 tissue. B, GFAP expression was $\sim 2$-fold (CA1, PtA) and $\sim 3$-fold higher (DG) in PLB4 brain tissue compared with age-matched control group. C, Brains from PLB4 mice with severe cognitive impairment (behaviorally assessed in water maze) presented with the highest levels of astrogliosis compared with PLB ${ }_{W T}$ mice. Scale bar, $50 \mu m$. Magnification $\times 63$. Asterisks indicate difference to control group; ${ }^{*} p<0.05,{ }^{* *} p<0.01,{ }^{* * *} p<0.001$. All data were normalized to WT and represent means + SEM.

\section{Behavioral profile of hBACE1 knock-in mice}

Phenotyping comprised physiological, motor, activity-related, and emotional aspects. No overt health effects were observed, PLB4 mice presented with an age-dependent weight reduction compared with controls from 6 months onward (predominantly in males). Conventional hyperexpression of bacel caused body weight loss as early as 7 weeks old (Harrison et al., 2003); somewhat contradictory, body weight reductions have also been described for bacel knock-out mice alongside protection against high-fat diet induced obesity (Meakin et al., 2012). BACE1 therefore seems to contribute to metabolic regulation; nevertheless, this phenotype had only minor consequences since sensory and motor functions were overall intact. Circadian activity patterns were also not altered in PLB4 mice; yet, motor activity was markedly decreased at 6 and 12 but not 3 months. By contrast, noveltyinduced ambulation was extended during habituation; this phenotype already occurred at 3 months and became progressively more severe, providing strong evidence for impaired formation of spatial representations in PLB4 subjects. Interestingly, APP-based models of amyloidosis also presented with slowed habituation combined with hyperactivity (Deacon et al., 2009; Walker et al., 2011). It is unlikely that prolonged habituation was due to stress or anxiety because both previous hBACE models (Harrison et al., 2003) and PLB4 mice presented with reduced anxiety-related behavior.

Further evidence for cognitive and spatial deficits was provided in the Y-maze (spatial working memory), water maze (spatial learning and reference memory), and STFP (semantic STM and LTM). Impairments in the Y-maze at 6 months are in line with the attributed role of amyloid (for review, see Lalonde et al., 2012). Working memory deficits were not detected in older PLB4 mice due to a significant aging effect in $\mathrm{PLB}_{\mathrm{WT}}$ animals. In the water maze paradigm, widely used to examine spatial navigation performance in AD mouse models (Stewart et al., 2011; Platt et al., 2011), a spatial acquisition deficit was apparent in PLB4 mice at 6 months. At 12 months, PLB4 mice continued to display impaired spatial learning yet no longer differed from WTs in recall, again due to reduced performance of the control group. In line with this, heightened levels of hBACE1 protein expression did not accelerate from 6 to 12 months of age in PLB4 forebrains; however, post-translational modifications and protein handling may well be affected, as strongly indicated by pathological APP processing, accompanied by elevated neuroinflammation in 12-month-old hbacel KI mice. We observed the most reliable $\mathrm{AD}$-relevant phenotypes with a clearest separation of controls and transgenic mice at 6 months of age, suggesting that introduction of hbacel resulted in premature aging in PLB4 mice. A comparison with the $\mathrm{PLB1}_{\text {Triple }}$ mouse generated via identical knock-in, uncovered that introduction of hbacel with a comparable expression profile had a more profound impact, i.e., $\mathrm{PLB1}_{\text {Triple }}$ mice were only impaired from 12 months (Platt et al., 2011; Ryan et al., 2013). Deficits in spatial learning are common in transgenic APP mice (Stewart et al., 2011), and have been attributed to a loss of spatial learning strategies (Janus, 2004; Brody and Holtzman, 2006). Intriguingly, both TgCRND8 mice and PSAPP mice, like PLB4, also increased the amount of chaining and random exploration trials.

Further characterization of cognitive phenotypes used a semantic-like STFP task that relies on nonspatial, socially acquired olfactory information. PLB4 mice displayed unaltered 
sociability, however, significant genotype- and age-related differences were observed during the discrimination task. Young PLB4 animals showed intact STM, but failed during LTM testing, i.e., the task with the high memory load. At 6 months, transgenic cohorts failed in both components thus confirming progressive deficits. Overall, this additional facet of cognitive impairment somewhat resembles a deficit described in 18-month-old 3xTg mice (Cassano et al., 2011), unfortunately no STFP data are available from other AD cohorts. The semantic deficit cannot be attributed to an olfactory loss described in Tg2576 mice (Wesson et al., 2010), as the "cookie test" was unaffected. STFP thus offer a species-adequate and convenient paradigm with close face validity, because semantic memory deficits are well documented in mild cognitive impairment patients (Venneri et al., 2008) and correlate with perirhinal/entorhinal as well hippocampal MRI phenotypes (Barbeau et al., 2012; Hirni et al., 2013).

\section{Molecular and immunocytochemical characterization of human BACE1 knock-in mouse}

In agreement with previous BACE1 models (Bodendorf et al., 2002; Mohajeri et al., 2004), we demonstrated that hbace1 knock-in induces pathologic processing of murine APP, with decreased full-length APP and heightened CTF $\beta$ fragments, but also increased levels of the toxic $\mathrm{A} \beta^{\star} 56$ and hexameric $\mathrm{A} \beta$ assemblies, whereas mature and aggregated $\mathrm{A} \beta$ plaques were sparse. Therefore, low levels of hBACE1 expression are sufficient to cause formation of $\mathrm{A} \beta$ oligomeric assemblies, mainly $\mathrm{A} \beta \beta^{\star} 56$ previously proposed as the most toxic form suggested to correlate with emergence of memory impairments in transgenic mice (Lesné et al., 2006, Billings et al., 2007) and in human AD (Lesné et al., 2013). Moreover, immunohistochemistry revealed strong anti-APP/A $\beta$ immunoreactivity in hippocampal regions. Intracellular accumulation was particularly pronounced in CA1 and DG, this may be caused by lack of secretion of generated $A \beta$ and its subsequent accumulation. Alternatively, released $\mathrm{A} \beta$ may be reabsorbed by neurons and stored in intracellular pools (Kanekiyo et al., 2013). Although the physiological or pathophysiological role of intraneuronal $\mathrm{APP} / \mathrm{A} \beta$ is not fully understood, evidence suggests that intraneuronal $A \beta$ accumulation occurs in brain areas affected in early human AD pathology, such as the hippocampus and entorhinal cortex (Gouras et al., 2000). In transgenic models, intraneuronal accumulation of $\mathrm{A} \beta$ precedes the formation of extracellular amyloid plaques and is likely to cause neurodegeneration (for review, see Bayer and Wirths, 2010). More importantly however, $A \beta$ readily aggregates into multimeric forms, a process initiated within the cells rather than in the extracellular space (Walsh et al., 2000). Future studies will confirm the exact identity of (toxic) intraneuronal amyloid species, with for example modified amyloid species (e.g., pyroglutmate or phosphorylated $\mathrm{A} \beta$ ) proposed as putative toxic molecular entities (Kumar et al., 2013).

Despite the paucity of plaques, extracellular emergence of $\mathrm{APP} / \mathrm{A} \beta$ was reliably detected surrounding neuronal cell bodies throughout the forebrain of PLB4 mice. Extracellular A $\beta$ accumulation is not essential for AD-like phenotypes (Ghosal et al., 2009) and may be inversely correlated to the build-up of intracellular A $\beta$ (Bahr et al., 1998; Oddo et al., 2006). In PLB4 hippocampal neurons, intense staining was present inside and surrounding neurones and frequent cell inclusions were detected. While this has not been investigated in detail, inclusions are indicative of apoptotic processes and were often surrounded by heavy extracellular A $\beta$ staining. Subcellular pathologies may reflect microdomains relevant for sorting and trafficking of APP/ $\mathrm{A} \beta$ and
BACE, and may play a crucial part in degenerative pathways (Das et al., 2013; Walter and van Echten-Deckert, 2013).

Further biochemical changes observed in PLB4 brain tissue related to GFAP levels (astrogliosis). We detected GFAP activation in hippocampal and cortical regions of PLB4 brains, with DG most strongly affected, thus matching the area of most intense hBACE immunoreactivity. The piriform cortex, responsible for olfactory information processing and memory, was also markedly inflamed, a putative cellular correlate for deficits observed in STFP. As brains were harvested from animals tested in OFWM, we divide tissue into good and bad learners based on their behavioral performance. A robust association between "learning phenotype" and the level of astrogliosis was identified, with CA1, and PtA and Pir cortices affected only in bad learners, labeling in DG was independent of cognitive scores. These findings are consistent with accumulation of APP/A $\beta$ in CA1 and DG of PLB4 brain tissue and suggest that levels of brain inflammation particularly in CA1 and cortical areas (rather than DG) correspond to cognitive deficits more accurately than i.e., amyloid plaque load.

In conclusion, this report is the first to comprehensively identify AD-relevant behavioral traits produced by hbace1 knock-in. Our results confirm that subtle hBACE1 expression is sufficient to recapitulate key aspects of human $\mathrm{AD}$ in mice, this was potentially overlooked in previous studies due to lack of plaque formation. We propose that the PLB4 mouse model not only provides a better understanding of BACE's physiological and pathophysiological roles, it also likely offers better face- and predictivevalidity for therapeutic intervention.

\section{References}

Ahmed RR, Holler CJ, Webb RL, Li F, Beckett TL, Murphy MP (2010) BACE1 and BACE2 enzymatic activities in Alzheimer's disease. J Neurochem 112:1045-1053. CrossRef Medline

Bahr BA, Hoffman KB, Yang AJ, Hess US, Glabe CG, Lynch G (1998) Amyloid $\beta$ protein is internalized selectively by hippocampal field CA1 and causes neurons to accumulate amyloidogenic carboxyterminal fragments of the amyloid precursor protein. J Comp Neurol 397:139-147. CrossRef Medline

Barbeau EJ, Didic M, Joubert S, Guedj E, Koric L, Felician O, Ranjeva JP, Cozzone P, Ceccaldi M (2012) Extent and neural basis of semantic memory impairment in mild cognitive impairment. J Alzheimers Dis 28:823-837. CrossRef Medline

Bayer TA, Wirths O (2010) Intracellular accumulation of amyloid-beta: a predictor for synaptic dysfunction and neuron loss in Alzheimer's disease. Front Aging Neurosci 2:8. CrossRef Medline

Billings LM, Green KN, McGaugh JL, LaFerla FM (2007) Learning decreases $\mathrm{A} \beta^{\star} 56$ and tau pathology and ameliorates behavioural decline in 3xTg-AD mice. J Neurosci 27:751-761. CrossRef Medline

Bodendorf U, Danner S, Fischer F, Stefani M, Sturchler-Pierrat C, Wiederhold KH, Staufenbiel M, Paganetti P (2002) Expression of human $\beta$-secretase in the mouse brain increases steady-state level of $\beta$-amyloid. J Neurochem 80:799-806. CrossRef Medline

Borchelt DR, Ratovitski T, van Lare J, Lee MK, Gonzales V, Jenkins NA, Copeland NG, Price DL, Sisodia SS (1997) Accelerated amyloid deposition in the brains of transgenic mice coexpressing mutant presenilin 1 and amyloid precursor proteins. Neuron 19:939-945. CrossRef Medline

Brody DL, Holtzman DM (2006) Morris water maze search strategy analysis in PDAPP mice before and after traumatic brain injury. Exp Neurol 197: 330-340. CrossRef Medline

Cai H, Wang Y, McCarthy D, Wen H, Borchelt DR, Price DL, Wong PC (2001) BACE1 is the major beta-secretase required for generation of A-beta peptides in neurons. Nat Neurosci 4:233-234. CrossRef Medline

Cassano T, Romano A, Macheda T, Colangeli R, Cimmino CS, Petrella A, LaFerla FM, Cuomo V, Gaetani S (2011) Olfactory memory is impaired in a triple transgenic model of Alzheimer's disease. Behav Brain Res 224: 408-412. CrossRef Medline

Chen Y, Huang X, Zhang YW, Rockenstein E, Bu G, Golde TE, Masliah E, Xu H (2012) Alzheimer's $\beta$-secretase (BACE1) regulates cAMP/PKA/ 
CREB pathway independently of $\beta$-amyloid. J Neurosci 32:11390-11395. CrossRef Medline

Chiocco MJ, Kulnane LS, Younkin L, Younkin S, Evin G, Lamb BT (2004) Altered amyloid- $\beta$ metabolism and deposition in genomic-based $\beta$-secretase transgenic mice. J Biol Chem 279:52535-52542. CrossRef Medline

Cole SL, Vassar R (2007) The basic biology of BACE1: A key therapeutic target for Alzheimer's disease. Curr Genomics 8:509-530. CrossRef Medline

Crawley JN, Goodwin FK (1980) Preliminary report of a simple animal behaviour for the anxiolytic effects of benzodiazepines. Pharmacol Biochem Behav 13:167-170. CrossRef Medline

Das U, Scott DA, Ganguly A, Koo EH, Tang Y, Roy S (2013) Activityinduced convergence of APP and BACE- 1 in acidic microdomains via an endocytosis-dependent pathway. Neuron 79:447-460. CrossRef Medline

Deacon RM, Koros E, Bornemann KD, Rawlins JN (2009) Aged Tg2576 mice are impaired on social memory and open field habituation tests. Behav Brain Res 197:466-468. CrossRef Medline

Dislich B, Lichtenthaler SF (2012) The membrane-bound aspartyl protease BACE1: molecular and functional properties in Alzheimer's disease and beyond. Front Physiol 3:8. CrossRef Medline

Eaton SL, Roche SL, Llavero Hurtado M, Oldknow KJ, Farquharson C, Gillingwater TH, Wishart TM (2013) Total protein analysis as a reliable loading control for quantative fluorescent Western blotting. PLoS One 8:e72457. CrossRef Medline

Fukumoto H, Cheung BS, Hyman BT, Irizarry MC (2002) $\beta$-Secretase protein and activity are increased in the neocortex of Alzheimer disease. Arch Neurol 59:1381-1389. CrossRef Medline

Galef BG, Wigmore SW (1983) Transfer of information concerning distant foods: a laboratory investigation of the "information-centre" hypothesis. Animal Behav 31:748-758. CrossRef

Garthe A, Behr J, Kempermann G (2009) Adult-generated hippocampal neurons allow flexible use of spatially precise learning strategies. PLoS One 4:e5464. CrossRef Medline

Gebhardt FM, Scott HA, Dodd PR (2010) Housekeepers for accurate transcript expression analysis in Alzheimer's disease autopsy brain tissue. Alzheimer's Dementia 6:465-474. CrossRef Medline

Ghosal K, Vogt DL, Liang M, Shen Y, Lamb BT, Pimplikar SW (2009) Alzheimer's disease-like pathological features in transgenic mice expressing the APP intracellular domain. Proc Natl Acad Sci U S A 106:1836718372. CrossRef Medline

Gil-Mohapel J, Brocardo PS, Choquette W, Gothard R, Simpson JM, Christie BR (2013) Hippocampal neurogenesis levels predict water maze search strategies in the ageing brain. PLoS One 8:e75125. CrossRef Medline

Gold G, Blouin JL, Herrmann FR, Michon A, Mulligan R, Duriaux Saïl G, Bouras C, Giannakopoulos P, Antonarakis SE (2003) Specific BACE1 genotypes provides additional risk for late-onset Alzheimer's disease in APOE $\varepsilon 4$ carriers. Am J Med Genet B Neuropsychiatr Genet 119B:44-47. CrossRef Medline

Gouras GK, Tsai J, Naslund J, Vincent B, Edgar M, Checler F, Greenfield JP, Haroutunian V, Buxbaum JD, Xu H, Greengard P, Relkin NR (2000) Intraneuronal $\mathrm{A} \beta_{42}$ accumulation in human brain. Am J Pathol 156:1520. CrossRef Medline

Grüninger-Leitch F, Schlatter D, Küng E, Nelböck P, Döbeli H (2002) Substrate and inhibitor profile of BACE (beta-secretase) and comparison with other mammalian aspartic proteases. J Biol Chem 277:4687-4693. CrossRef Medline

Harrison SM, Harper AJ, Hawkins J, Duddy G, Grau E, Pugh PL, Winter PH, Shilliam CS, Hughes ZA, Dawson LA, Gonzalez MI, Upton N, Pangalos MN, Dingwall C (2003) BACE1(beta-secretase) transgenic and knockout mice: identification of neurochemical deficits and behavioural changes. Mol Cell Neurosci 24:646-655. CrossRef Medline

Hébert SS, Horré K, Nicolaï L, Papadopoulou AS, Mandemakers W, Silahtaroglu AN, Kauppinen S, Delacourte A, De Strooper B (2008) Loss of microRNA cluster miR-29a/b-1 in sporadic Alzheimer's disease correlates with increased BACE1/ $\beta$-secretase expression. Proc Natl Acad Sci U S A 105:6415-6420. CrossRef Medline

Hemming ML, Elias JE, Gygi SP, Selkoe DJ (2009) Identification of $\beta$-secretase (BACE1) substrates using quantitative proteomics. PLoS One 4:e8477. CrossRef Medline

Hirni DI, Kivisaari SL, Monsch AU, Taylor KI (2013) Distinct neuroanatomical basis of episodic and semantic memory performance in Alzheimer's disease. Neuropsychologia 51:930-937. CrossRef Medline
Janus C (2004) Search strategies used by APP transgenic mice during navigation in the Morris water maze. Learn Mem 11:337-346. CrossRef Medline

Kanekiyo T, Cirrito JR, Liu CC, Shinohara M, Li J, Schuler DR, Shinohara M, Holtzman DM, Bu G (2013) Neuronal clearance of amyloid- $\beta$ by endocytic receptor LRP1. J Neurosci 33:19276-19283. CrossRef Medline

Kim DY, Carey BW, Wang H, Ingano LA, Binshtok AM, Wertz MH, Pettingel WH, He P, Lee VM, Woolf CJ, Kovacs DM (2007) BACE1 regulates voltage-gated sodium channels and neuronal activity. Nat Cell Biol 9:755-764. CrossRef Medline

Kimura R, Devi L, Ohno M (2010) Partial reduction of BACE1 improves synaptic plasticity, recent and remote memories in Alzheimer's disease transgenic mice. J Neurochem 113:248-261. CrossRef Medline

Kobayashi D, Zeller M, Cole T, Buttini M, McConlogue L, Sinha S, Freedman S, Morris RG, Chen KS (2008) BACE1 gene deletion: impact on behavioural function in a model of Alzheimer's disease. Neurobiol Aging 29: 861-873. CrossRef Medline

Koss DJ, Riedel G, Bence K, Platt B (2013a) Store-operated Ca ${ }^{2+}$ entry in hippocampal neurons: regulation by protein tyrosine phosphotase PTP1B. Cell Calcium 53:125-138. CrossRef Medline

Koss DJ, Drever BD, Stoppelkamp S, Riedel G, Platt B (2013b) Agedependent changes in hippocampal synaptic transmission and plasticity in the PLB1 $1_{\text {Triple }}$ Alzheimer mouse. Cell Mol Life Sci 70:2585-2601. CrossRef Medline

Kuhn PH, Koroniak K, Hogl S, Colombo A, Zeitschel U, Willem M, Volbracht C, Schepers U, Imhof A, Hoffmeister A, Haass C, Roßner S, Bräse S, Lichtenthaler SF (2012) Secretome protein enrichment identifies physiological BACE1 protease substrates in neurons. EMBO J 31:31573168. CrossRef Medline

Kumar S, Wirths O, Theil S, Gerth J, Bayer TA, Walter J (2013) Early intraneuronal accumulation and increase aggregation of phosphorylated Abeta in a mouse model of Alzheimer's disease. Acta Neuropathol 125: 699-709. CrossRef Medline

Laird FM, Cai H, Savonenko AV, Farah MH, He K, Melnikova T, Wen H, Chiang HC, Xu G, Koliatsos VE, Borchelt DR, Price DL, Lee HK, Wong PC (2005) BACE1, a major determinant of selective vulnerability of the brain to amyloid- $\beta$ amyloidogenesis, is essential for cognitive, emotional, and synaptic functions. J Neurosci 25:11693-11709. CrossRef Medline

Lalonde R, Fukuchi K, Strazielle C (2012) APP transgenic mice for modelling behavioural and psychological symptoms of dementia (BPSD). Neurosci Biobehav Rev 36:1357-1375. CrossRef Medline

Lesné SE, Ming YK, Kotilinek L, Kayed R, Glabe CG, Yang A, Gallagher M, Ashe KH (2006) A specific amyloid- $\beta$ protein assembly in the brain impairs memory. Nature 440:352-357. CrossRef Medline

Lesné SE, Sherman MA, Grant M, Kuskowski M, Schneider JA, Bennett DA, Ashe KH (2013) Brain amyloid- $\beta$ oligomers in ageing and Alzheimer's disease. Brain 136:1383-1398. CrossRef Medline

Luo Y, Bolon B, Kahn S, Bennett BD, Babu-Khan S, Denis P, Fan W, Kha H, Zhang J, Gong Y, Martin L, Louis JC, Yan Q, Richards WG, Citron M, Vassar R (2001) Mice deficient in BACE1, the Alzheimer's betasecretase, have normal phenotype and abolished beta-amyloid generation. Nat Neurosci 4:231-232. CrossRef Medline

Meakin PJ, Harper AJ, Hamilton DL, Gallagher J, McNeilly AD, Burgess LA, Vaanholt LM, Bannon KA, Latcham J, Hussain I, Speakman JR, Howlett DR, Ashford ML (2012) Reduction in BACE1 decreases body weight, protects against diet-induced obesity and enhances insulin sensitivity in mice. Biochem J 441:285-296. CrossRef Medline

Mohajeri MH, Saini KD, Nitsch RM (2004) Transgenic BACE expression in mouse neurons accelerates amyloid plaque pathology. J Neural Transm 111:413-425. CrossRef Medline

Nicolaou M, Song YQ, Sato CA, Orlacchio A, Kawarai T, Medeiros H, Liang Y, Sorbi S, Richard E, Rogaev EI, Moliaka Y, Bruni AC, Jorge R, Percy M, Duara R, Farrer LA, St Georg-Hyslop P, Rogaeva EA (2001) Mutations in the open reading frame of the $\beta$-site APP cleaving enzyme (BACE) locus are not a common cause of Alzheimer's disease. Neurogenetics 3:203-206. Medline

Oddo S, Caccamo A, Smith IF, Green KN, LaFerla FM (2006) A dynamic relationship between intracellular and extracellular pools of $\mathrm{A} \beta$. Am J Pathol 168:184-194. CrossRef Medline

Odeh F, Leergaard TB, Boy J, Schmidt T, Riess O, Bjaalie JG (2011) Atlas of transgenic Tet-Off $\mathrm{Ca}^{2+} /$ clmodulin-dependent protein kinase II and prion protein promoter activity in the mouse brain. Neuroimage 54: 2603-2611. CrossRef Medline 
Ohno M, Cole SL, Yasvoina M, Zhao J, Citron M, Berry R, Disterhoft JF, Vassar R (2007) BACE1 gene deletion prevents neuron loss and memory deficits in 5XFAD APP/PS1 transgenic mice. Neurobiol Dis 26:134-145. CrossRef Medline

Pellow S, Chopin P, File SE, Briley M (1985) Validation of open:closed arm entries in an elevated plus-maze as a measure of anxiety in the rat. J Neurosci Methods 14:149-167. CrossRef Medline

Platt B, Drever B, Koss D, Stoppelkamp S, Jyoti A, Plano A, Utan A, Merrick G, Ryan D, Melis V, Wan H, Mingarelli M, Porcu E, Scrocchi L, Welch A, Riedel G (2011) Abnormal cognition, sleep, EEG and brain metabolism in a novel knock-in Alzheimer mouse, PLB1. PLoS One 6:e27068. CrossRef Medline

Riedel G, Fadda P, McKillop-Smith S, Pertwee RG, Platt B, Robinson L (2009) Synthetic and plant-derived cannabinoid receptor antagonist show hypophagic properties in fasted and non-fasted mice. Br J Pharmacol 156:1154-1166. CrossRef Medline

Roberds SL, Anderson J, Basi G, Bienkowski MJ, Branstetter DG, Chen KS, Freedman SB, Frigon NL, Games D, Hu K, Johnson-Wood K, Kappenman KE, Kawabe TT, Kola I, Kuehn R, Lee M, Liu W, Motter R, Nichols NF, Power M, et al. (2001) BACE knock-out mice are healthy despite lacking the primary beta-secretase activity in brain: implications for Alzheimer's disease therapeutics. Hum Molec Genet 10:1317-1324. CrossRef Medline

Robinson L, Guy J, McKay L, Brockett E, Spike RC, Selfridge J, De Sousa D, Merusi C, Riedel G, Bird A, Cobb SR (2012) Morphological and functional reversal of phenotypes in a mouse model of Rett syndrome. Brain 135:2699-2710. CrossRef Medline

Robinson L, Plano A, Cobb S, Riedel G (2013) Long-term home cage activity scans reveal lowered exploratory behaviour in symptomatic female Rett mice. Behav Brain Res 250:148-156. CrossRef Medline

Ryan D, Koss D, Porcu E, Woodcock H, Robinson L, Platt B, Riedel G (2013) Spatial learning impairments in PLB1 $1_{\text {Triple }}$ knock-in Alzheimer's mice are task-specific and age-dependent. Cell Mol Life Sci 70:2603-2619. CrossRef Medline

Sambamurti K, Kinsey R, Maloney B, Ge YW, Lahiri DK (2004) Gene structure and organization of the human $\beta$-secretase (BACE) promoter. FASEB J 18:1034-1036. CrossRef Medline

Schoenfeld R, Moenich N, Mueller FJ, Lehmann W, Leplow B (2010) Search strategies in a human water maze analogue analysed with automatic classification methods. Behav Brain Res 208:169-177. CrossRef Medline

Sinha S, Anderson JP, Barbour R, Basi GS, Caccavello R, Davis D, Doan M, Dovey HF, Frigon N, Hong J, Jacobson-Croak K, Jewett N, Keim P, Knops J, Lieberburg I, Power M, Tan H, Tatsuno G, Tung J, Schenk D, et al. (1999) Purification and cloning of amyloid precursor protein $\beta$-secretase from human brain. Nature 402:537-540. CrossRef Medline

Stewart S, Cacucci F, Lever C (2011) Which memory task for my mouse? A systematic review of spatial memory performance in the Tg2576 Alzheimer's mouse model. J Alzheimers Dis 26:105-126. CrossRef Medline

Vassar R, Bennett BD, Babu-Khan S, Kahn S, Mendiaz EA, Denis P, Teplow DB, Ross S, Amarante P, Loeloff R, Luo Y, Fisher S, Fuller J, Edenson S,
Lile J, Jarosinski MA, Biere AL, Curran E, Burgess T, Louis JC, et al. (1999) $\beta$-secretase cleavage of Alzheimer's amyloid precursor protein by the transmembrane asparyric protease BACE. Science 286:735-741. CrossRef Medline

Venneri A, McGeown WJ, Hietanen HM, Guerrini C, Ellis AW, Shanks MF (2008) The anatomical bases of semantic retrieval deficits in early Alzheimer's disease. Neuropsychologia 46:497-510. CrossRef Medline

Vianna MR, Alonso M, Viola H, Quevedo J, de Paris F, Furman M, de Stein ML, Medina JH, Izquierdo I (2000) Role of hippocampal signalling pathways in long-term memory formation of a nonassociative learning task in the rat. Learn Mem 7:333-340. CrossRef Medline

Walker JM, Fowler SW, Miller DK, Sun AY, Weisman GA, Wood WG, Sun GY, Simonyi A, Schachtman TR (2011) Spatial learning and memory impairment and increase locomotion in a transgenic amyloid precursor protein mouse model of Alzheimer's disease. Behav Brain Res 222:169175. CrossRef Medline

Walsh DM, Tseng BP, Rydel RE, Podlisny MB, Selkoe DJ (2000) The oligomerization of amyloid $\beta$-protein begins intracellularly in cells derived from human brain. Biochemistry 39:10831-10839. CrossRef Medline

Walter J, van Echten-Deckert G (2013) Cross-talk of membrane lipids and Alzheimer-related proteins. Mol Neurodegener 8:34. CrossRef Medline

Wang H, Song L, Laird F, Wong PC, Lee HK (2008) BACE1 knock-outs display deficits in activity-dependent potentiation of synaptic transmission at mossy fiber to CA3 synapses in the hippocampus. J Neurosci 28:8677-8681. CrossRef Medline

Welinder C, Ekblad L (2011) Coomassie staining as loading control in Western blot analysis. J Proteome Res 10:1416-1419. CrossRef Medline

Wesson DW, Levy E, Nixon RA, Wilson DA (2010) Olfactory dysfunction correlates with amyloid-beta burden in an Alzheimer's disease mouse model. J Neurosci 30:505-514. CrossRef Medline

Willem M, Garratt AN, Novak B, Citron M, Kaufmann S, Rittger A, DeStrooper B, Saftig P, Birchmeier C, Haass C (2006) Control of peripheral nerve myelination by the $\beta$-secretase BACE1. Science 314:664666. CrossRef Medline

Wolfer DP, Lipp HP (2000) Dissecting the behaviour of transgenic mice: is it the mutation, the genetic background, or the environment? Exp Physiol 85:627-634. CrossRef Medline

Yang LB, Lindholm K, Yan R, Citron M, Xia W, Yang XL, Beach T, Sue L, Wong P, Price D, Li R, Shen Y (2003) Elevated beta-secretase expression and enzymatic activity detected in sporadic Alzheimer's disease. Nat Med 9:3-4. CrossRef Medline

Yang M, Crawley JN (2009) Simple behavioural assessment of mouse olfaction. Curr Protoc Neurosci 8:8.24. CrossRef Medline

Youmans KL, Tai LM, Nwabuisi-Heath E, Jungbauer L, Kanekiyo T, Gan M, Kim J, Eimer WA, Estus S, Rebeck GW, Weeber EJ, Bu G, Yu C, Ladu M] (2012) APOE4-sepcific changes in $\mathrm{A} \beta$ accumulation in a new transgenic mouse model of Alzheimer disease. J Biol Chem 287:41774-41786. CrossRef Medline 